AperTO - Archivio Istituzionale Open Access dell'Università di Torino

\title{
Preferences for Well-Being and Life Satisfaction
}

\section{This is the author's manuscript}

Original Citation:

Availability:

This version is available http://hdl.handle.net/2318/150164

since 2018-04-24T02:37:01Z

Published version:

DOI:10.1007/s11205-017-1566-8

Terms of use:

Open Access

Anyone can freely access the full text of works made available as "Open Access". Works made available under a Creative Commons license can be used according to the terms and conditions of said license. Use of all other works requires consent of the right holder (author or publisher) if not exempted from copyright protection by the applicable law. 


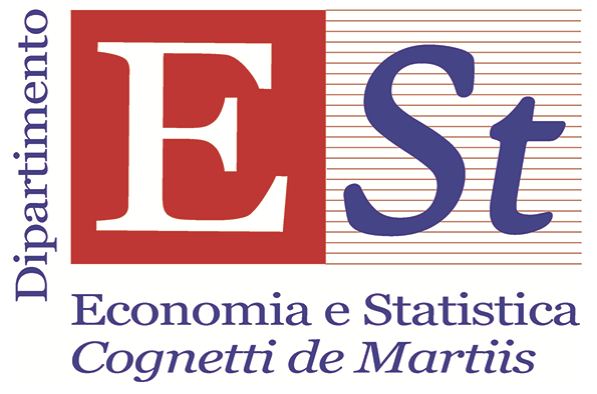

\section{Working Paper Series}

\section{$21 / 14$}

\section{"DE GUSTIBUS ERRARI (POT)EST": UTILITY MISPREDICTION, PREFERENCES FOR WELL-BEING AND LIFE SATISFACTION}

\section{LEONARDO BECCHETTI and PIERLUIGI CONZO}





\title{
"De gustibus errari (pot)est": utility misprediction, preferences for well-being and life satisfaction ${ }^{\S}$
}

\author{
Leonardo Becchetti, University of Rome "Tor Vergata" $"$ \\ Pierluigi Conzo, University of Turin ${ }^{+}$
}

This version: July, 2014

\begin{abstract}
The life satisfaction literature generally focuses on how life events affect subjective well-being. Through a contingent valuation survey we test whether well-being preferences have significant impact on life satisfaction. A sample of respondents is asked to simulate a policymaker decision consisting in allocating scarce financial resources among 11 well-being domains. Consistently with the utility misprediction hypothesis, we find that the willingness to invest more in the economic well-being domain is negatively correlated with life satisfaction. Our findings are shown to be robust when we account for unobservables related to economic fragility and non-random sample selection. Reverse causality and omitted variable bias are controlled for with instrumental variables and a sensitivity analysis on departures from exogeneity assumptions. Subsample estimates document that the less educated are more affected by the problem.
\end{abstract}

Keywords: life satisfaction, well-being preferences, utility misprediction, subjective well-being.

JEL numbers: A13, D64, H50, I31

\footnotetext{
$\S$ The paper is part of a research coordinated by Laboratorio RicercAzione from Formazione Quadri Terzo Settore and sponsored by Fondazione con il Sud. The authors thank all the scientific board of FQTS, ISTAT and Fondazione con il Sud for their support, Arnstein Aasve, Stefano Bartolini, Letizia Mencarini, Tommaso Proietti, Maurizio Pugno, Alois Stutzer for comments and suggestions, Sante Orsini, Roberto Porciello, Fabiola Riccardini and Focusmarketing for their precious coordination and research assistance in building the online survey and providing relevant data. Finally we thank the newspapers Messaggero, Avvenire and Unità for hosting the survey.

$\dagger$ Dept. of Economics, University of Rome Tor Vergata, Via Columbia 2, I-00133 Roma; email: becchetti@economia.uniroma2.it

¥Dept. of Economics and Statistics “Cognetti de Martiis”, University of Turin; email: pierluigi.conzo@unito.it
} 


\section{Introduction}

Several authors have provided rationales explaining why individuals may mispredict utility (see, among others, Lebergott 1993, Lane 1991, Frank 1999 and Frey et al. 2004). Among the most relevant of them we find underestimation of asymmetric adaptation to the effects of extrinsic/intrinsic aspects to subjective well-being, ${ }^{1}$ distorted past memories due to peak-end rules ${ }^{2}$ and effects of marketing policies advertising comfort goods more than stimulus goods. ${ }^{3}$ The same line of thought argues that utility misprediction may explain the often observed positive (negative) correlation between life satisfaction and intrinsic (extrinsic) life goals (e.g. Kasser and Ryan 1996; Sirgy 1997; Frey and Stutzer, 2004). This is because the above-mentioned rationales lead individuals to overestimate the impact on life satisfaction of extrinsic and material goods. Advocates of the utility misprediction hypothesis must however overcome the error correction argument (why people do not correct their misprediction) and, from an empirical point of view, empirical findings in support of this hypothesis must be proven to be robust to reverse causality and endogeneity.

\footnotetext{
${ }^{1}$ The life satisfaction literature documents on this point that individuals adapt quickly to positive changes in income (van Praag 1993, Easterlin 2001, Stutzer 2004, Di Tella et al. 2010) while much less so to negative non pecuniary events such as illnesses, shocks to relational goods and job losses (e.g. Easterlin 2005, Oswald and Powdthavee 2008, Luhmann et al. 2012).

${ }^{2}$ Frey and Stutzer (2005) argue that extrinsic attributes are more related to peak emotions which are demonstrated to distort retrospective assessments of feelings in psychological experiments (Kahneman, 1999). Due to such peak emotions materialistic events are remembered with more satisfaction.

${ }^{3}$ The concepts of stimulus and comfort goods were first introduced by Scitovsky (1992). Stimulus goods are goods whose consumption is not possible without previous investment in activities or skills which make such consumption possible. The concept may be applied for instance to cultural, language or sport abilities. The main example provided by Scitovsky is the enjoyment of culture and arts and study and investment in humanistic culture accumulates the crucial "capital" which allows to enjoy this kind of stimulus good. In alternative, comfort goods are goods which provide immediate satisfaction but may create in the long run dependence and may weaken investment in the acquisition of the skills necessary to consume stimulus goods, thereby contributing to create a happiness paradox (Pugno, 2013). Since comfort goods may produce dependence, and consequently a much more stable flow of profits, they are by far more advertised than stimulus goods. Frey and Stutzer (2013) argue that advertising emphasizes extrinsic more than intrinsic aspects of goods. Our point is that advertising pushes toward comfort goods which in turn require more economic wellbeing to be consumed but negatively affect life satisfaction. Addiction to comfort goods and insufficient investment in skills required to consume stimulus goods may contribute to explain why the negative effects of utility misprediction may not be easily corrected in a dynamic perspective.
} 
We aim to contribute to this literature by documenting from an original source of empirical evidence a strong and statistically significant negative correlation between life satisfaction and materialistic preferences proxied for by expenditure preferences for economic well-being. We show that our evidence is robust to non random sample selection, endogeneity and reverse causality. The starting point of our investigation is the process of construction of equitable and sustainable wellbeing indicators (Benessere Equo e Sostenibile) enacted by the Italian Statistical Institute in 2011 following the guidelines of the Sen/Stiglitz commission (see section 2 for details). The result of such process is the identification of 11 well-being domains which were regarded as fundamental by representatives of different groups of the Italian population. Our research builds on such classification by asking individuals to simulate the hypothetical policymaker decision to allocate a given sum among the 11 domains. Our work is novel from this point of view since, to our knowledge and with the exception of Becchetti et al. (2013), papers investigating the determinants of political preferences have so far concentrated their effort on single factors affecting support for a specific well-being domain (i.e. environmental sustainability, redistribution), while never looking at how weights across different domains are distributed.

Empirical findings related to our question on well-being preference weights document that individuals who would invest more in economic well-being are significantly less satisfied with their life. The maintained assumption behind our reasoning is that willingness to invest more in economic wellbeing in the simulated policymaker action should mirror excess time dedicated to its pursuit in private life thereby producing negative consequences on life satisfaction. Under this assumption, our results are consistent with the utility misprediction hypothesis since individuals who overestimate utility from material well-being (and underestimate utility from other nonmaterial domains, like e.g. socializing) should declare higher willingness to invest in economic well-being (rather than, e.g., in social relationships) and, at the same time - due to a systematic estimation error in their utility estimation - lower life satisfaction than individuals who declare 
lower willingness to invest in the same domain while attaching higher value to other non-material domains.

Most of the empirical work in the paper aims to disentangle the above discussed utility misprediction interpretation of the observed nexus from the alternative interpretations of omitted variable bias, endogeneity and reverse causality.

A first alternative rationale may in fact be that available explanatory variables do not adequately capture all economic well-being dimensions. According to this interpretation, individuals would invest more in economic well-being while being relatively less satisfied with life because they are relatively worse off in terms of unobservable economic well-being components (i.e., they may be relatively more indebted or suffer from other forms of financial fragility not captured by information available to the researcher). In order to control for this problem we introduce income satisfaction among regressors in our benchmark specification. Such variable not only captures the impact of all unobservables related to economic well-being but also accounts for a potential gap between expectations and realisations in terms of material satisfaction which may produce a negative impact on life satisfaction even when income and other unobservable economic components are at levels which may be objectively considered as adequate.

A second rationale for our findings, alternative to utility misprediction, is reverse causality: reduced life satisfaction may push individuals to search compensation for their unhappiness in material goods. According to this view, whatever the causes of unhappiness (idiosyncratic time invariant psychological traits or life events) their effects on life satisfaction may produce a reverse causality nexus from the latter to materialistic preferences due to such compensatory reaction.

We control for these alternative interpretations with instrumental variable regressions and a sensitivity analysis à la Imbens (2003) which allows us to evaluate the robustness of our results to the introduction of a simulated confounder when relaxing the standard conditional independence assumption. Note as well that the sensitivity analysis also provides a sound alternative to the 
introduction of income satisfaction among regressors when controlling for unobservables related to financial fragility.

Being robust to alternative interpretations tested with these econometric tools, our results therefore provide confirmation that utility misprediction is an explanation of our main result. These results have relevant implications for economic theory since they suggest the need of broadening our theoretical horizons from a standard framework for economic modeling in which preferences are generally regarded as exogenous and time invariant (de gustibus non est disputandum) to a framework in which individuals progressively discover their preferences in a noisy environment in which psychological or sociological distortions may make this work not simple (de gustibus errari potest).

The paper is divided into six sections (including introduction and conclusions). In the second section we describe the institutional process of construction of the equitable and sustainable wellbeing indicators which are at the root of our empirical work. In the third section we illustrate the design of our empirical investigation. In the fourth section we provide and comment descriptive findings and hypothesis testing. In the fifth section we illustrate and discuss our econometric results and robustness checks controlling for omitted variable bias, non-representativeness of our sample, endogeneity and reverse causality; we further provide subsample estimates in order to check how (below/above median) education and income affect misprediction. The final section concludes.

\section{The BES process}

The selection of proper well-being indicators is of crucial importance since it relates to the ultimate ends of socioeconomic activity and policymaking. The well-known limits of GDP in capturing the multiplicity of well-being dimensions have recently led the Sen-Stiglitz commission to recommend 
and provide guidelines for the adoption of a more articulated set of indicators. ${ }^{4}$ Italy was one of the first countries to follow the advice launching in 2011 a three-phases process. In the first, $\mathrm{CNEL}^{5}$ members representing different stakeholders in the Italian society were asked to identify the most important well-being domains. In the second, ad hoc commissions of experts were created for each domain with the goal of identifying a proper set of indicators which could adequately capture specific different well-being dimensions. In the third, the set of indicators were presented to the CNEL stakeholders for validation.

The result of this process led to the definition of the following twelve BES domains: ${ }^{6}$
01. Health
02. Education and training
03. Work and life balance
04. Economic well-being
05. Social relationship
06. Politics and Institutions
07. Safety
08. Subjective well-being
09. Natural and cultural heritage
10. Environment
11. Research and innovation
12. Quality of services

A first description of Italy on their basis was presented the $12^{\text {th }}$ March 2012. A nice property of the Italian process is its attempt to overcome the trade-off between subjective indicators (which may

\footnotetext{
${ }^{4}$ Downloadable at http://www.stiglitz-sen-fitoussi.fr/documents/rapport anglais.pdf.

${ }^{5}$ CNEL composition (sixty-four councillors elected for five years) well reflect the heterogeneity of the Italian society. Forty-eight members are representatives of public and private-sector producers of goods and services: twenty-two of these represent employees, three represent the public and private leaders and managers, nine represent self-employed workers; seventeen are industry representatives, nominated by a Decree of the President of the Republic, after being proposed by the President of the Council of Ministers, upon deliberation of the Council of Ministers. Six members are representatives of social service and voluntary organisations.

${ }^{6}$ The complete list of the 134 specific indicators created in the different BES domains by ISTAT is attached in Appendix A. For a more complete and detailed information on the process of BES creation see the English version of the ISTAT/BES official website http://www.misuredelbenessere.it/index.php?id=48.
} 
fall into the "happy slave" Sen's critique $)^{7}$ and objective indicators which tend to be paternalistic (that is, imposed on the population by a commission of experts) (Sugden, 2008). BES indicators are not paternalistic since domains in the first step of its creation process are proposed from stakeholders of the Italian society (see footnote 5) and the indicators suggested by commissions of experts for each domain are validated by the same stakeholders in the third final step. At the same time they do not fall into the happy slave critique since the role of subjective well-being indicators is very limited. ${ }^{8}$

\section{The survey design and the theoretical framework}

Our empirical analysis is based on an online survey we launched on March 2013. The survey appeared on three main Italian newspapers (Messaggero, ${ }^{9}$ Avvenire, ${ }^{10}$ Unità $^{11}$ ) and on several other minor newspapers and websites. ${ }^{12} \mathrm{We}$ insert checks and identification processes in the online survey which prevent the same respondent from filling the form more the once. We terminated it by end of July collecting around 3,346 complete questionnaires. ${ }^{13}$

\footnotetext{
${ }^{7}$ With subjective wellbeing indicators we may have the paradox of individuals who behave as "happy slaves" reducing aspirations to the low level of their achievements, thereby lacking of desire for social progress. Sen illustrates the point by arguing that "The defeated and the downtrodden come to lack the courage to desire things that others more favourably treated by society desire with easy confidence" (Sen, 1985: 15).

${ }^{8}$ Subjective indicators occupy in the BES only one of the 12 domains (n.8 subjective wellbeing) while few subjective indicators are included to complement objective indicators in some selected domains (i.e. those of economic wellbeing, health, safety) (for further details see Appendix A and B). Note as well that, in spite of its limits and potential manipulations, subjective wellbeing worth being measured since satisfaction/lack of satisfaction with life is highly likely to have repercussions on objective indicators such as health, social capital and political stability.

${ }^{9}$ Messaggero, has a reputation of moderate conservative political orientation and is the fifth most red Italian newspaper (excluding sport newspapers).

${ }^{10}$ Avvenire, is the most important Italian catholic newspaper. As such it reflects the ideological divide of Italian believers which are equally divided between right and left wing orientation.

${ }^{11}$ Unità has a left wing tradition being the official newspaper of the Democrat Party.

${ }^{12}$ These are Forum Nazionale Terzo Settore, FQTS, ARCI, ConVol, CSV Net, Labsus, Dignità del lavoro, Auser, Avis, Anpas, Bandiera Gialla, La perfetta letizia, Mondo alla Rovescia, Confini online, Il Metapontino.it, ARCI, Campania, Blog vitobiolchini, Domos (domotica sociale).

${ }^{13}$ An inescapable limit of our online survey is that it is not representative of the Italian population. Online compilation in fact automatically selects a subsample of individuals who tend to be relatively younger and more educated than average. This limit is at the same time an interesting aspect of our survey since the composition of our sample anticipates characteristics of the future population which is bound to be more educated in the future. Also for this reason we may have a specific interest in investigating the relationship at stake in this specific group of the population. From another point of view lack of representativeness of our sample with respect to the Italian population is a common characteristics of many econometric studies which are not interested in descriptive traits of the universe of reference but
} 
In the main question around which we concentrate our interest we ask respondents to allocate the hypothetical sum of 100 million euros to promote well-being improvement in one of the 11 (subjective wellbeing excluded) considered BES domains (see the attached questionnaire in the Appendix B). This question is followed by sub-questions in which respondents are asked to identify the five priorities in terms of indicators in each of the considered domains. ${ }^{14}$ The questionnaire is completed by questions aimed to provide standard socio-demographic information. Needless to say, given the questionnaire structure and the presence of several questions, it is almost impossible that respondents may understand that the researcher is interested, in the specific case of this paper, in investigating the link between life satisfaction and well-being expenditure on the economic wellbeing domains.

The logic behind our main question of interest (desired investment in the 11 domains) may be resumed in the following theoretical framework illustrated by Becchetti et al. (2013) where it is assumed that each individual $i$ has the following utility function defined over the set of the $j=1, \ldots, J$ domains

$$
\begin{gathered}
U_{i}=\left(E\left[W_{i 1}\left(M_{i 1}\right)\right], E\left[W_{i 2}\left(M_{i 2}\right)\right], \cdots, E\left[W_{i J}\left(M_{i J}\right)\right]\right) \\
M_{i 1}+M_{i 2}+\cdots+M_{i J}=M
\end{gathered}
$$

with $W_{j}$ being the $j$-th well-being domain and $M_{i j}$ is the total amount that the individual $i$ would like to invest in the domain $\mathrm{j}$ (with the total amount to be invested among different domains being equal for all individuals).

First order conditions from utility maximization imply that individuals equalize the marginal utility arising from investing one euro in each of the different domains, that is

to econometric links in that specific sample. Last but not least, subsample estimates for high/low educated respondents help us to correct the bias and to understand what happens in the subsample of the less educated which is closer to country average characteristics. We also correct our main estimates for non-representativeness of our sample with specific design weights described in subsection 4.4.

${ }^{14}$ Note that the survey question changes when we ask preferences about subdomain specific indicators (from the simulation of an invested sum to an more general indication of priorities). This is because some of these indicators are subjective and it is not clear whether others may be affected by government expenditure (see Appendix B). 


$$
\frac{\partial U_{i}}{\partial E\left[W_{i 1}\right]} \cdot \frac{\partial E\left[W_{i 1}\right]}{\partial M_{i 1}}=\frac{\partial U_{i}}{\partial E\left[W_{i 2}\right]} \cdot \frac{\partial E\left[W_{i 2}\right]}{\partial M_{i 2}}=\cdots=\frac{\partial U_{i}}{\partial E\left[W_{i J}\right]} \cdot \frac{\partial E\left[W_{i J}\right]}{\partial M_{i J}}
$$

What illustrated above clearly shows that the marginal utility of the investment of one euro in a given domain is the product of two factors: the expected impact of one euro invested on the advancement of that well-being domain and the effect of such advancement on individual utility.

Based on this theoretical framework individual choices reflect beliefs on what politicians should do to maximize their well-being even though their expectations on the first of the two factors might be wrong. To make an example individuals may overestimate the impact of one euro spent on a given domain (i.e., safety) on the improvement of well-being in that domain (i.e. $\frac{\partial E\left[W_{i 1}\right]}{\partial M_{i 1}}>\frac{\partial W_{i 1}}{\partial M_{i 1}}$ ) and therefore find desirable high investment in it or may, on the contrary, consider that domain very important but erroneously believe that investment in that given domain is useless (i.e. $\frac{\partial E\left[W_{i 1}\right]}{\partial M_{i 1}}<$ $\left.\frac{\partial W_{i 1}}{\partial M_{i 1}}\right)$. In this sense it should be better to define what we observe as expenditure well-being preferences more than well-being preferences. Consider as well that incorrect expectations of the kind described above cancel out if we assume that they are normally distributed in our sample. Furthermore, the discrepancy between the expected marginal improvements in a well-being domain by one-euro invested in that domain $\left(\frac{\partial E\left[W_{i 1}\right]}{\partial M_{i 1}}\right)$ and the real marginal impact of such investment $\left(\frac{\partial W_{i 1}}{\partial M_{i 1}}\right)$ can be due to region-specific factors like, for instance, lack of trust in local politicians and/or regional budget constraints which can be controlled for in the econometric analysis by introducing regional fixed effects. It is as well reasonable to assume that the incorrect expectation problem is less serious in the case of the economic well-being domain - the main object of our inquiry - since a government has many direct or indirect effective ways to affect this domain (such as subsidies, tax allowances, etc.). 
What must be also remarked is that the typical distortion of the contingent evaluation literature should not apply to our question. Individuals tend to provide biased answers when they want to convey a given message to the interviewer or when they are asked to make evaluations which can strategically affect their payoffs (i.e., they tend to declare lower willingness to pay for public goods in order to free ride or they misreport income for fear of being taxed) (Carson et al., 2001). The question we pose has no power of producing such an effect. In our case if the respondent wants to emphasize the importance of a given well-being domain she/he just has to declare to be willing to invest a higher amount on it. Hence the strategic goal should lead in this case to a true and not to a biased declaration.

\section{Descriptive and empirical findings}

In Table 1 we report summary statistics of the main variables used in the econometric analysis. The variable used is the standard cognitive measure of subjective well-being (life satisfaction). ${ }^{15}$ Consistently with most of the empirical literature the distribution of self-reported life satisfaction is right skewed with most values concentrated between 6 and 9. Respondents' self-declared life satisfaction level (life_sat) is on average 7.2 while their average level of satisfaction with economic conditions is 5.5 (income_sat).

The preferred well-being domain in which respondents would invest is health (16.5 percent, driver_health), followed by education and training (13.5 percent, driver_edu), work and life balance (10.3 percent, driver_job) and economic well-being (9.6 percent, driver_ecowell), the least preferred domain being politics and institution (3.9 percent, driver politics). Differences in well-

\footnotetext{
${ }^{15}$ Using self-declared levels of life satisfaction as a proxy for individual utility is a standard approach in the literature on subjective well-being and happiness economics (see, e.g., Frey and Stutzer 2002, Layard 2005, Di Tella and MacCulloch 2006, Stutzer and Frey 2010), as well as in psychology (e.g. Kahneman et al. 1999, Diener et al. 1999). As is well known alternative subjective wellbeing measures are of affective (negative/positive affect) and eudaimonic (evaluation of the sense of one's own life) type. The cognitive measure we adopt is however probably the most widely used at least in the economic literature on life satisfaction.
} 
being preferences across domains are not negligible given that equal distribution of investment among them would predict an average investment of around 9 percent for each.

When it comes to socio-demographic characteristics we find that most survey participants have the Italian nationality (Italian), are from the "South or Islands" Italian macro-area (South and Islands), have an open-ended type of employment (open-ended contract) and declare that their income ranges between 15.000 and 30.000 euros; roughly 13 percent of the sample is unemployed (not working). About 35 percent of respondents have a high school diploma, 39 percent a Master's degree, while a negligible share of the sample has no education $(0.3$ percent $) .{ }^{16}$ As far as the civil status is concerned, the majority of individuals is married/cohabitant (57 percent) while about 35 percent is single.

In Figure 1 we plot money allocation (as percentage of the total) between the two domains of economic well-being and social-relations (without considering all the others) against declared levels of life satisfaction in order to emphasize the relationship between life satisfaction and preferences for material vs. non-material well-being. Figure 1 clearly shows the presence of a negative nexus between life satisfaction and investment in economic well-being especially at the left tail of the life satisfaction distribution. Among individuals with low levels of satisfaction (between 1 and 3) the amount spent in economic well-being over the total of the two domains of economic well-being and social relationship (the most typical intrinsic goal among the 11 domains) is largely above $60 \%$. On the contrary, at the highest level of life satisfaction (between 8 and 10) investment in the economic well-being and social relations domains tend to converge.

A negative (positive) nexus between preferences for material (non-material) well-being - proxied for by investment in economic well-being (social-relations) domain - and life satisfaction is also found when comparing material vs. non-material investment preferences by levels of life satisfaction under parametric and non-parametric tests (see Table 2). As already suggested by

\footnotetext{
${ }^{16}$ This clearly reflect a bias toward high education due to the non random sample selection implicit in our research (only those who voluntarily accept to fill a questionnaire online may participate). We will address this problem with adhoc design weights in subsection 4.4 .
} 
Figure 1, low levels of life satisfaction are associated with stronger preferences toward material than toward non-material well-being, the differences being statistically significant under both parametric and non parametric tests for the interval of low levels of life satisfaction and when the entire life satisfaction range is considered. On the contrary, consistently with what found in Figure 1 at high levels of life satisfaction we do not detect significant differences between investment in the economic well-being driver and in social-relations.

The descriptive evidence provided so far highlights a negative nexus between investment in the economic well-being domain and life satisfaction. In order to further investigate the rationale behind such a negative relationship and account for potential endogeneity by controlling for a set of individual's socio-demographic and economic characteristics as well as regional fixed effects, we estimate the following baseline model:

$$
\begin{aligned}
\text { Life_sat }_{i}= & \alpha_{0}+\sum_{j=1}^{J} \beta_{s} \text { BES_Driver }_{i s}+\sum_{k=1}^{K} \gamma_{k} \text { SocioDem }_{i, k}+\sum_{l=1}^{L} \delta_{l} \text { DIncomeClas }_{i, l} \\
& +\sum_{q=1}^{Q} \lambda_{q} \text { DJobStatus }_{i, q}+\sum_{v=1}^{V} \chi_{v} \text { DSource }_{i, v}+\sum_{g=1}^{G} \kappa_{g} \text { DArea }_{i, g}+\varepsilon_{i}
\end{aligned}
$$

where the dependent variable (Life_sat) is subject $i$ 's self-declared level of life satisfaction on a 1-10 scale $(1=$ completely unsatisfied, $10=$ completely satisfied $), B E S$ Driver is the share of money hypothetically invested by subject $i$ in the $j$-th BES domain (social well-being being the omitted category), SocioDem is a set of respondent's sociodemograpic characteristics including political orientation (RightWing) expressed by respondents on a $-10 /+10$ scale $(-10$ extreme left, +10 extreme right), a (0/1) dummy for Italian nationality (Italian), a set of dummies for the respondent's age class picking up five-year age intervals (the 30-35 age class is the omitted benchmark), education level dummies (primary-middle education being the omitted benchmark), a gender dummy taking value one if the respondent is female and zero otherwise and MaritalStatus dummies picking up the Divorced, Single, Separated and Widowed conditions (Married/Cohabitant being the omitted 
benchmark). The specification also includes the respondent's income class (DIncomeClass) and job status (DJobStatus) dummies, with Income_class $<15.000 €$ and Not Working/Unemployed/Looking for a Job being the excluded categories respectively. Individual's geographic location (i.e. depending on the specification, either North-East, North-West or South and Islands macroregions of Italy or region dummies) are also controlled for with DArea dummies. Dsource includes a set of dummy variables capturing the source of information through which the respondent came to know about the survey. The omitted benchmark is represented by those who filled the questionnaire through word of mouth (i.e. acquaintances/friends). The Dsource variables may capture part of the unobserved individual's traits which can represent a possible source of bias in our econometric estimates.

Table 3 reports results from an ordered logit estimate of different specifications of the baseline model in (3). In column 1 we estimate the baseline model without introducing the BES investment decisions and find that women, non-married/non-cohabitant, unemployed and/or low income individuals tend to report a lower degree of life satisfaction, while more educated and right-wing oriented individuals report a higher degree of life satisfaction. Interestingly, those who came to know about this questionnaire through sources not involving direct social activities (i.e. blog, social networks, etc.) are less satisfied with their life than those who were instead directly informed about it by friends/acquaintances. As argued above, the introduction of such dummies may reduce potential endogeneity issues by capturing individuals' unobserved traits (e.g., sociability) which are both correlated with BES investment choices and life satisfaction.

In Table 3, column 2 we introduce the share of money that individuals would allocate to the different BES well-being domains. Our results confirm the above-mentioned negative nexus between life satisfaction and investment in economic well-being. In particular, our main finding suggests that higher expenditure preferences for the economic well-being driver relatively to the social well-being one (the excluded category) is detrimental for life satisfaction. As a consequence (if alternative rationales of reverse causality and endogeneity may be ruled out) the utility 
maximization hypothesis that individuals optimally balance their investment in each domain so to maximise their final utility (see eq. 2) seems to be rejected by the data. Even though reduced in magnitude, this main effect is robust to the introduction of the respondent's level of satisfaction with economic conditions (income_sat) accounting for the aspiration-realisation gap and both measurement errors and omitted variables concerning respondents' economic and financial status (Table 3, column 3), as well as to the introduction of regional fixed effects accounting for unobserved region-specific quality of institutions and/or local public expenditure (Table 3, column 4).

Based on this last specification, we evaluate the economic significance of our main result and find that a one percentage-point increase in investment in economic well-being increases (decreases) the probability of declaring a life satisfaction level below (above) the sample median by .57 (.64) percentage points. A graphical evidence of the magnitude of driver_ecowell is also shown in Figure 2 in which marginal effects from a proportional increase in the investment in economic well-being with respect to the maximum potential investment (i.e. 100 units) are plotted against the probability that life_sat is below the sample median (i.e., seven).

The main econometric results described above are also shown in the scatterplot in Figure 3 in which the predicted probability of declaring a level of life satisfaction below the sample median is plotted against the predicted values from an OLS regression of the amount of units invested in the economic well-being (driver_ecowell) on a set of controls as in (3). The scatterplot analysis confirms the negative relationship between life satisfaction and the amount of money invested in the economic well-being driver.

\section{Correcting for endogeneity}

So far we have described the relationship between preferences for material well-being and life satisfaction in terms of statistical correlation. In this section we check the robustness of our main 
finding and try to correct for endogeneity arising from reverse causality and omitted variable bias by using respectively an instrumental variable approach (Subsection 4.1), discussing heterogeneous effects on life satisfaction from the investment on economic well-being by comparing subsamples of individuals by income class and education level (Subsection 4.2) and performing a sensitivity analysis (Imbens, 2003) on departures from exogeneity assumptions (Subsection 4.3). In addition, our main estimates are finally corrected for a possible bias deriving from the non-representativeness of our sample due to the voluntary-based response to the survey (Subsection 4.4).

\subsection{Instrumental variable regressions}

In what follows we implement an instrumental variable approach in order to control for endogeneity and reverse causality and account for the existence of a causal nexus between preferences for material well-being (driver_ecowell) and life satisfaction pointing to an opposite direction with respect to that presented in (3).

Before doing this, we first estimate the following baseline specification

$$
\begin{aligned}
\text { Life_sat }_{i}= & \alpha_{0}+\beta \text { Driver_ecowell }_{i}+\pi \text { Income_sat }_{i}+\sum_{k=1}^{K} \gamma_{k} \text { SocioDem }_{i, k} \\
& +\sum_{l=1}^{L} \delta_{l} \text { DIncomeClass }_{i, l}+\sum_{q=1}^{Q} \lambda_{q} \text { DJobStatus }_{i, q} \\
& +\sum_{v=1}^{V} \chi_{v} \text { DSource }_{i, v}+\sum_{g=1}^{G} \kappa_{g} \text { DRegion }_{i, g}+\varepsilon_{i}
\end{aligned}
$$

which is similar to the model in Table 3, column 4 with the only exception that the benchmark BES domain is now composed by all the other domains not included in (4) (since all other domains are excluded from right hand side variables). The rationale behind such a specification hinges on the necessity to instrument the main choice-variable of interest for this study which is suspected of endogeneity - Driver_ecowell - with instruments which are valid and relevant as we will document below. 
Table 4, columns 1-2 report results from the OLS estimates of eq. 4. The negative relationship between investment in economic well-being and life satisfaction is confirmed also under this model specification. In addition, since the omitted BES benchmark is now composed by all the BES domains but Driver_ecowell, the new estimates reinforce our main finding since those investing more in the economic well-being domain with respect to all the other domains appear to be less satisfied with their life (Table 4, column 1). In column 2 we re-estimate the previous specification by replacing life satisfaction, investment in economic well-being and satisfaction with economic conditions with a ratio between the individual-i's value for the latter variables and their regional sample average calculated excluding the individual $i$ (see variable legend in the Appendix). The introduction of these ratios allows us to reduce the additional endogeneity due to the high correlation and/or simultaneity among Driver_ecowell, Life_sat and Income_sat. Estimation results reported in column 2 (Table 4) are consistent with those in column 1 and, more in general, with our core finding.

We then instrument Driver_ecowell with its sample average computed in individual-i's region excluding $i$ 's investment decision in the economic well-being domain. More specifically, for each individual $i$ living region $j$ we construct the variable Mean_EW $W_{-i, j}=\frac{\sum_{j} \text { Driver_ecowell }_{-i, j}}{n_{j}-1}$ (where $n_{j}$ is the total number of individuals in the sample living in region $j$ ) and use it to instrument Driver_ecowell in the above-described estimates in columns 1-2 (Table 4). Once regional characteristics are controlled for in the reduced form equation, the validity of the chosen instrument is guaranteed by the plausible assumption that the regional average investment in economic wellbeing affects life satisfaction only through the individual's investment in that domain (which, as explained above, has not been included when computing the regional mean). ${ }^{17}$ As an indirect test for the validity of the exclusion restriction we check for the significance of the instrumental variable

\footnotetext{
${ }^{17}$ Becchetti et al. (2013) document that individual well-being preferences are not affected by objective indicators, that is, they are not correlated to scarcity/abundance of the well-being dimension at regional level. This evidence reinforces even more our validity assumption since, in case of correlation, average preferences could affect individual life satisfaction through objective achievements in the specific wellbeing indicator at regional level.
} 
in the main equation and find that Mean_EW $W_{-i, j}$ does not significantly account for the variation in the life satisfaction variable (columns 3-4, Table 4). Possible theoretical channels making such an exclusion restriction valid can derive from social imitation and/or cultural norms which explain also the correlation between other's average and individual's investment in economic well-being. The existence and the magnitude of such a correlation provides support for the relevance of our instrumental variable which is also empirically confirmed by ad-hoc statistical tests commented below.

Results from IV estimates are consistent with those from OLS estimates described above (i.e. they do not exhibit the typically larger standard errors and changes in coefficient magnitudes which occur when the set of instruments has not enough variability) and are reported in columns 5-6 of Table 4. Instrument relevance and the absence of weak instrument bias is confirmed by two statistical checks, i.e. i) the F-statistics from the first stage are relatively high (i.e. 12.73 and 9.18 for the specification in columns 5 and 6 respectively) and ii) the F-statistics from the Stock and Yogo (2005)'s weak-instrument test are greater than all the related Stock and Yogo critical values. We finally re-estimate the previous instrumental variable models accounting for the specific characteristics of the dependent variables both in the first and the second stage, i.e. categorical (life_sat) or censored (driver_ecowell, ratio_LS and ratio_EW). Estimation results reported in columns 7-10 (Table 4) confirm all the previous findings. Incidentally, the individual level of satisfaction with her/his own economic conditions enters significantly both the first and second stage but with an opposite sign, i.e. it positively affects life satisfaction but it does negatively for investment in economic well-being. Therefore, by including income_sat in both stages we are also likely to capture omitted variables representing an additional source of bias like, for instance, the unobserved economic and financial conditions and/or the aspiration-realisation gap which can simultaneously influence both life satisfaction and investment in material well-being.

\subsection{Heterogeneous effects}


Columns 8 and 10 (Table 4) show that being female, right-wing oriented, young, less educated, under a seasonal contract or redundancy fund benefits (relative to the being unemployed) and wealthier are among the factors which positively influence the investment in the economic wellbeing domain. In order to test for sample heterogeneous effects of the economic well-being investment we re-estimate the IV specification in columns 7-8 in Table 4 by comparing subsamples of individuals below/above the median income class and education level. Columns 1-2 in Table 5 show that individuals with income class above the median sample level face a negative impact of economic well-being investment on life satisfaction while the effect of investment in economic well-being is not significant for those reporting an income class level not above the sample median (columns 3-4, Table 5). In other terms, the former show higher preferences for the economic wellbeing domain but derive lower life satisfaction from it relative to the latter. A possible interpretation is that higher income individuals seem to be more subject to utility misprediction due to higher consumption of (comfort, extrinsic) goods subject to adaptation (see Easterlin, 2001 and Stutzer, 2004). The same occurs for those who are less educated (i.e. have at least a high school diploma) and hence more exposed to media influence and/or imitation when consuming "status" or comfort goods (see footnote 3) - since they invest more in the economic well-being domain but also enjoy less from it in terms of life-satisfaction (columns 5-6, Table 5) relative to the higher educated respondents (columns 7-8, Table 5).

\subsection{Sensitivity Analysis}

As already discussed above, an additional source of bias in our estimates may derive from the exclusion of an unobserved variable which is correlated with both life satisfaction and investment in the economic well-being driver, even after accounting, as we do, for individual economic and financial fragility and aspirations. This is because personal traits (i.e. for instance, entrepreneurial skills, friendliness, assertiveness, envy, lack of generosity) or family-background values can act potentially as omitted factors which - if not introduced in our econometric analysis - make it hard to assume that investment in the economic well-being driver is uncorrelated with the error term. 
Since the above mentioned variables are unobservable and in order to take into account for their potential role, we check whether our results are robust to the departure from the materialismexogeneity assumption without relying on the validity and exogeneity of an instrument as above.

By exploiting the econometric advances in the policy evaluation literature, we implement the Imbens (2003)'s sensitivity analysis based on i) modelling relaxations of the unconfoundedness assumption through the simulation of parameter values underling an unobserved variable's distribution, and ii) assessing whether the main effect of interest vanishes under plausible assumptions on those parameter values. Since this approach has been proposed originally in the context of policy evaluation, the main effect of interest in the related literature is the "average treatment effect" (ATE) of a policy intervention (the "treatment variable") on an outcome variable. In our case, the treatment variable $(T)$ can be thought as the probability of an individual's investment in economic well-being below the sample mean whereas the outcome $(Y)$ is life satisfaction. We then model the possible channels through which an unobserved variable $(U)$ influences $T$ and $Y$ leading to a bias of a fixed amount in the ATE estimation. We finally use the observed controls $(X)$ to benchmark the plausibility of the existence of such an unobservable. ${ }^{18}$

The baseline model on which we implement the sensitivity analysis is reported in Table 3 , column 2. In order to construct our "treatment" variable, we replace all the BES_Driver variables with an indicator equal to 1 if the respondent $i$ invested in the economic driver more than the sample average and zero otherwise, i.e. $I_{\text {Driver_ecowell }_{i}}>\frac{\sum_{i} \text { Driver_ecowell }_{i}}{N}(N$ is the sample size $)$. Consequently, in this specification the ATE (estimated under exogeneity) captures the impact of a high investment in economic well-being on life satisfaction.

Figures 4-6 show the results from the general sensitivity analysis performed using the algorithm developed by Harada (2012). In Figure 4 the solid curve represents the set of partial R-squares for $\mathrm{U}$ corresponding to an ATE which is half of the baseline one (i.e., 0.37), while in Figure 5 it

\footnotetext{
${ }^{18}$ See Imbens (2003) for further details on this method and Blattman and Annan (2010) for an application.
} 
represents the set of partial R-squares for $U$ that lead to an ATE equal to 0.01 (i.e. zero impact of investment in economic well-being on life satisfaction). Finally, in Figure 6 the solid curve is the set the partial R-squares for U which correspond to an ATE no longer significant at $95 \%$ confidence level. The "+" signs are the partial R-square values for the X covariates of the baseline model. More specifically, Figures 4-6 show the explanatory power of each of the observed regressors for $\mathrm{T}$ $\left(I_{\text {Driver_ecowell }}>\frac{\sum_{i} \text { Driver_ecowell }_{i}}{N}\right)$ and Y (life_sat $)$. The vertical axis reports the marginal increase in the R-square from adding the covariate to a regression of life satisfaction on all other covariates while the horizontal axis measures the marginal influence of the covariate on the variation in $\mathrm{T}$. The solid curve can therefore be interpreted as a threshold beyond which the simulated $U$ is so influential to reduce the baseline ATE by half (Figure 1), completely (Figure 2) or to make it no longer statistically significant (Figure 3).

Our findings document that all the observed regressors lie below the solid curve in all our plots. This implies that, in order to change the magnitude and significance of our baseline ATE, any unobserved factor $\mathrm{U}$ influencing both $\mathrm{T}$ and $\mathrm{Y}$ should implausibly account for more variation in the $\mathrm{Y}$ than actually do all the $\mathrm{X}$ covariates, including marital status, income, education, employment characteristics, and age which - as outlined before - are shown to play a significant role on life satisfaction. The overall conclusions from our check are that the ATE of a large investment on economic well-being on life satisfaction estimated under the assumption of exogeneity is still significant and does not change in magnitude when we relax such assumption by simulating a third omitted factor with "reasonable" parameter values.

\subsection{Non-random sample selection}

Since our sample is mainly composed by individuals who answer to the survey on a voluntary basis, non-representativeness may potentially be an additional source of bias. In particular, as it can be noticed from descriptive statistics, our sample is mostly composed by high educated, aged 40-45 individuals living in the South and Islands. Even though non-random sampling and consequent self- 
selection issues can be partially accounted for through the IV estimation and the heterogeneous effects analysis implemented in the previous subsections, we perform an additional robustness check by re-estimating the models in Tables 3 and 4 with a calibration weighting approach. Design weights for the above-mentioned demographic characteristics are derived by merging our nonrandom sample with the national census (random) one. More specifically, we append the micro-data from the 2012 national census to our dataset and estimate on the whole (larger) sample a logistic regression of the individual's probability of being in the census on gender, education level, age and region of residence. We then take the inverse of the predicted probabilities and use them to weight our survey respondents in the main estimates. ${ }^{19}$ Results are reported in the Appendix (Tables A2A3) and are extremely similar to the unweighted ones from Tables 3-4, thereby suggesting that nonrandom feature of our sample does not lead to a severe estimation bias.

\section{Conclusions}

In this paper we exploit the unique opportunity of a database combining information on selfreported life satisfaction with individual preferences for government expenditure on different wellbeing domains. Our main finding is a strong and significant negative correlation between subjective well-being and willingness to invest more in the economic well-being domain. We document that utility misprediction is a relevant driver of our findings, net of the alternative and equally plausible interpretations related to endogeneity, reverse causality, omitted variable bias and measurement errors on our set of regressors (especially unobservables related to our objective economic wellbeing measures). We reach this conclusion since our main findings remain significant when: i) we control for income satisfaction with which we capture all unobservables related to economic wellbeing and the potential gap between achievements and expectations in the economic well-being domain; ii) we use an instrumental variable approach iii) we perform a sensitivity analysis which

\footnotetext{
${ }^{19}$ See Kott (2006), Sarndal (2007) and Skinner (1999) for details on calibration weighting procedures for non-random samples.
} 
relaxes the conditional independence assumption and iv) we use ad hoc design weights to correct for non-random sampling. Interestingly, higher income and lower educated respondents seem to be more exposed to utility misprediction, possibly because of income-adaptation (the former) and exposure to the media or status-based imitation (the latter).

The robustness of the utility misprediction rationale in the interpretation of our findings implies non-trivial consequences for the economic literature. Most of our models are based on the assumption of rational individuals with time invariant preferences who "know their type", i.e. are fully aware of the characteristics of their utility function. We find on the contrary not just that "de gustibus est disputandum" (in the sense that each individual is perfectly informed about her/his time invariant preferences) but also that "de gustibus errandum (pot)est". Empirical support for the hypothesis of utility misprediction thereby opens the way to the much broader and general framework assuming utility functions which are not perfectly known to individuals and whose content can be revealed after a discovery process aimed to overcome the distortions that psychological (underestimation of asymmetric adaptation, peak-end rules) or social (impact of advertising) mechanisms may produce. The suggestion stemming from this paper is therefore that the economic literature should adopt a broader view on preferences and incorporate concepts on them which are well known in sociology, psychology and marketing.

Our robust empirical evidence on the existence utility misprediction calls for further investigation on the determinants of and the rationales behind the persistence of such prediction errors and on the factors which might reduce them. Regarding this last point, several policy suggestions which may be drawn from the above-mentioned view. Regulation or taxation reducing psychological or social factors influencing the discovery process of one's own preferences can create positive effects on individual well-being. Implications can be huge in other fields such as limits to TV advertising (especially for children) as it already occurs in several countries even though web exposure reduce the effectiveness of these measures. According to our subsample estimates in section 4.2 similar positive effects on economic well-being may arise from investment in education which may help 
individual to reduce the noise produced by such psychological and social disturbances on preference discovery.

\section{References}

1. Becchetti, L., Corrado, L. and Fiaschetti, M. (2013), The heterogeneity of wellbeing "expenditure" preferences: evidence from a simulated allocation choice on the BES indicators, CEIS Research Paper N. 297

2. Blattman C. and Annan A. J. (2010), The Consequences of Child Soldiering, Review of Economics and Statistics, 42(4).

3. Carson, R.T., Flores, N.E. and Meade, N.F. (2001), Contingent valuation: controversies and evidence, Environmental and Resource Economics, 19: 173-210.

4. Di Tella, R. and MacCulloch, R. (2006), Some Uses of Happiness Data in Economics, Journal of Economic Perspectives, 20(1): 25-46.

5. Di Tella, R., Haisken-DeNew, J.P. and MacCulloch, R. (2010), Happiness Adaptation to Income and to Status in an Individual Panel, Journal of Economic and Behavior Organization, 76(3): 834-852.

6. Diener, E., Suh, E.M., Lucas, R.E., Smith, H.L. (1999), Subjective Well- Being: Three Decades of Progress. Psychological Bulletin, 125(2): 276-303.

7. Easterlin, R.A. (2001), Income and Happiness: Towards a Unified Theory, Economic Journal, 111(473): 465-484.

8. Easterlin, R.A. (2005), A Puzzle for Adaptive Theory, Journal of Economic Behavior and Organization, 56(4): 513-21.

9. Frank, R. H. (1999). Luxury Fever. Why Money Fails to Satisfy in an Era of Excess. New York: Free Press.

10. Frey, B.S. and Stutzer, A. (2002), What Can Economists Learn from Happiness Research?, Journal of Economic Literature, 40(2): 402-435.

11. Frey, B.S. and Stutzer, A. (2004), Economic Consequences of Mispredicting Utility, IEW Working Paper No. 218.

12. Frey, B.S. and Stutzer, A. (2005), Does the Political Process Mitigate or Accentuate Individual Biases due to Mispredicting Future Utility?. In: McCaffery E. and Slemrod J. (eds). Behavioral Public Finance. New York (N.Y.): Russell Sage Foundation. 
13. Frey, B.S. and Stutzer, A. (2013), Economics and the Study of Individual Happiness. In: Susan A. David, Ilona Boniwell and Amanda Conley Ayers (eds.). The Oxford Handbook of Happiness. Oxford: Oxford University Press: 431-447.

14. Frey, B.S., Benz, M. and Stutzer, A. (2004), Introducing Procedural Utility: Not Only What but also How Matters, Journal of Institutional and Theoretical Economics, 160(3): 377-401.

15. Harada, M. (2012), Generalized Sensitivity Analysis, Working paper.

16. Imbens, G.W. (2003), Sensitivity to Exogeneity Assumptions in Program Evaluation, American Economic Review, 93: 126-32.

17. Kahneman, D. (1999), Objective Happiness. In: Kahneman, D., Diener, E. and Schwarz, N. (eds), Well-Being: The Foundations of Hedonic Psychology. New York: Russell Sage Foundation: 3-25.

18. Kahneman, D., Diener, E. and Schwarz N. (1999), Well-Being: The Foundation of Hedonic Psychology. New York: Russell Sage Foundation.

19. Kasser, T. and Ryan, R.M. (1996), Further Examining the American Dream: Differential Correlates of Intrinsic and Extrinsic Goals, Personality and Social Psychology Bulletin, 22(3): 280-287.

20. Kott, P. S. (2006), Using Calibration Weighting to Adjust for Nonresponse and Coverage Errors, Survey Methodology, 32 (2): 133-142.

21. Lane, R.E. (1991), The Market Experience. Cambridge: Cambridge University Press.

22. Layard, P.R.G. (2005), Happiness: Lessons From a New Science. New York and London: Penguin.

23. Lebergott, S. (1993), Pursuing Happiness: American Consumers in the Twentieth Century. Princeton, NJ: Princeton University Press.

24. Luhman, M., Hofmann, W., Eid, M. and Lucas, R.E. (2012), Subjective Well-Being and Adaptation to Life Events: A Meta-Analysis, Journal of Personality and Social Psychology, 102(3): 592-615.

25. Oswald, A. and Powdthaveem N. (2008), Does Happiness Adapt? A Longitudinal Study of Disability with Implications for Economists and Judges, Journal of Public Economics, 92(5-6): 1061-1077.

26. Pugno, M. (2013), Scitovsky and the income-happiness paradox, The Journal of SocioEconomics, 43: 1-10

27. Sarndal, C. E. (2007), The Calibration Approach in Survey Theory and Practice, Survey Methodology, 33 (2): 99-119.

28. Scitovsky, T. (1992)[1976], The Joyless Economy. Oxford: Oxford University Press.

29. Sen, A.K. (1985), Well-being, Agency and Freedom: The Dewey Lectures 1984, Journal of Philosophy, 82: 69-221.

30. Sirgy, M.J. (1997), Materialism and Quality of Life, Social Indicators Research, 43(3): 227260. 
31. Skinner, C. (1999), Calibration Weighting and Non-Sampling Errors, Research in Official Statistics, 2: 33-43.

32. Stock, J. and Yogo, M. (2005), Testing for Weak Instruments in Linear IV Regression. In: Andrews DWK Identification and Inference for Econometric Models. New York: Cambridge University Press: 80-108.

33. Stutzer, A. (2004), The role of income aspirations in individual happiness, Journal of Economic Behavior \& Organization, 54(1): 89-109

34. Stutzer, A. and Frey, B.S. (2010), Recent Advances in the Economics of Individual Subjective Well-Being, Social Research: An International Quarterly, 77(2): 679-714.

35. Sugden, R. (2008), Capability, Happiness, and Opportunity. In: Bruni, L., Comim, F. and Pugno, M. (2008), Capabilities and Happiness, Oxford University Press.

36. Van Praag, B.M.S. (1993), The Relativity of the Welfare Concept. In: Martha Nussbaum and Amarthya K. Sen (eds). The Quality of Life. Oxford: Clarendon: 362-416. 
Table 1 - Descriptive statistics

\begin{tabular}{|c|c|c|c|c|c|c|c|}
\hline Variable & Obs & Mean & Std. Dev. & Min & Max & Confidence & ntervals \\
\hline Life_sat & 3346 & 7.177 & 1.813 & 1 & 10 & 7.051 & 7.302 \\
\hline Income_sat & 3346 & 5.539 & 2.407 & 1 & 10 & 5.300 & 5.779 \\
\hline Driver_ecowell & 3346 & 9.639 & 12.302 & 0 & 100 & 6.515 & 12.763 \\
\hline Driver_health & 3346 & 16.484 & 11.161 & 0 & 100 & 15.376 & 17.591 \\
\hline Driver_edu & 3346 & 13.470 & 7.894 & 0 & 100 & 12.894 & 14.047 \\
\hline Driver_job & 3346 & 10.282 & 8.236 & 0 & 100 & 9.695 & 10.868 \\
\hline Driver_social & 3346 & 7.142 & 6.125 & 0 & 100 & 6.528 & 7.756 \\
\hline Driver_politics & 3346 & 3.858 & 4.564 & 0 & 100 & 3.699 & 4.016 \\
\hline Driver_security & 3346 & 6.892 & 5.992 & 0 & 100 & 6.622 & 7.161 \\
\hline Driver_cultur & 3346 & 7.454 & 4.896 & 0 & 50 & 6.937 & 7.970 \\
\hline Driver_environ & 3346 & 8.410 & 5.359 & 0 & 50 & 7.928 & 8.891 \\
\hline Driver_innovation & 3346 & 8.581 & 5.884 & 0 & 100 & 7.842 & 9.320 \\
\hline Driver_serviqual & 3346 & 7.789 & 5.552 & 0 & 100 & 7.361 & 8.218 \\
\hline Ratio_EW & 3346 & 1.004 & 0.865 & 0 & 12.442 & 0.954 & 1.054 \\
\hline Ratio_IS & 3346 & 1.001 & 0.433 & 0.147 & 2.309 & 0.986 & 1.016 \\
\hline Italian & 3346 & 0.982 & 0.132 & 0 & 1 & 0.972 & 0.993 \\
\hline Female & 3346 & 0.530 & 0.499 & 0 & 1 & 0.498 & 0.563 \\
\hline RightWing & 3346 & -2.582 & 4.690 & -10 & 10 & -2.922 & -2.243 \\
\hline Age class & 3346 & 5.171 & 2.746 & 1 & 13 & 4.900 & 5.441 \\
\hline North-East & 3346 & 0.115 & 0.319 & 0 & 1 & 0.049 & 0.181 \\
\hline North-West & 3346 & 0.162 & 0.368 & 0 & 1 & 0.058 & 0.266 \\
\hline South-and-Islands & 3346 & 0.466 & 0.499 & 0 & 1 & 0.293 & 0.639 \\
\hline Center & 3346 & 0.115 & 0.319 & 0 & 1 & 0.049 & 0.181 \\
\hline Open-Ended Contract & 3346 & 0.393 & 0.489 & 0 & 1 & 0.349 & 0.438 \\
\hline Fixed-Term Contract & 3346 & 0.112 & 0.316 & 0 & 1 & 0.100 & 0.125 \\
\hline Seasonal Contract & 3346 & 0.021 & 0.144 & 0 & 1 & 0.009 & 0.034 \\
\hline Independent Contractor/Freelancer & 3346 & 0.156 & 0.363 & 0 & 1 & 0.139 & 0.173 \\
\hline Redundancy Fund Benefits & 3346 & 0.006 & 0.077 & 0 & 1 & 0.003 & 0.009 \\
\hline Redundancy Worker & 3346 & 0.007 & 0.086 & 0 & 1 & 0.004 & 0.011 \\
\hline Housewife & 3346 & 0.019 & 0.136 & 0 & 1 & 0.013 & 0.024 \\
\hline Student & 3346 & 0.060 & 0.237 & 0 & 1 & 0.038 & 0.082 \\
\hline Retired & 3346 & 0.099 & 0.299 & 0 & 1 & 0.081 & 0.118 \\
\hline Not working & 3346 & 0.126 & 0.332 & 0 & 1 & 0.102 & 0.150 \\
\hline Income class: <15 & 3346 & 0.292 & 0.455 & 0 & 1 & 0.249 & 0.334 \\
\hline Income class: $15-30$ & 3346 & 0.361 & 0.480 & 0 & 1 & 0.340 & 0.382 \\
\hline Income class: 30-50 & 3346 & 0.183 & 0.387 & 0 & 1 & 0.154 & 0.212 \\
\hline Income class: 50-100 & 3346 & 0.065 & 0.246 & 0 & 1 & 0.050 & 0.080 \\
\hline Income class: > 100 & 3346 & 0.010 & 0.097 & 0 & 1 & 0.005 & 0.014 \\
\hline Income class: no answer & 3346 & 0.090 & 0.286 & 0 & 1 & 0.076 & 0.103 \\
\hline No school & 3346 & 0.003 & 0.055 & 0 & 1 & 0.001 & 0.005 \\
\hline Primary school & 3346 & 0.010 & 0.099 & 0 & 1 & 0.002 & 0.017 \\
\hline Middle school & 3346 & 0.064 & 0.244 & 0 & 1 & 0.043 & 0.084 \\
\hline High School & 3346 & 0.347 & 0.476 & 0 & 1 & 0.320 & 0.374 \\
\hline Vocational High School & 3346 & 0.028 & 0.164 & 0 & 1 & 0.020 & 0.036 \\
\hline Bachelor' Degree & 3346 & 0.134 & 0.341 & 0 & 1 & 0.121 & 0.148 \\
\hline Masters' Degree & 3346 & 0.387 & 0.487 & 0 & 1 & 0.353 & 0.421 \\
\hline Phd & 3346 & 0.027 & 0.164 & 0 & 1 & 0.017 & 0.038 \\
\hline Newspaper/magazines & 3346 & 0.090 & 0.286 & 0 & 1 & 0.065 & 0.115 \\
\hline Online newspapers & 3346 & 0.276 & 0.447 & 0 & 1 & 0.196 & 0.357 \\
\hline Social network/blogs & 3346 & 0.129 & 0.335 & 0 & 1 & 0.104 & 0.153 \\
\hline Institutions/public entities & 3346 & 0.012 & 0.110 & 0 & 1 & 0.007 & 0.018 \\
\hline Social network/third sector/associationism and coooperation & 3346 & 0.166 & 0.372 & 0 & 1 & 0.100 & 0.232 \\
\hline Third sector manager training program & 3346 & 0.102 & 0.303 & 0 & 1 & 0.068 & 0.136 \\
\hline Other & 3346 & 0.013 & 0.111 & 0 & 1 & 0.008 & 0.017 \\
\hline Friends & 3346 & 0.212 & 0.409 & 0 & 1 & 0.149 & 0.274 \\
\hline Single & 3346 & 0.354 & 0.478 & 0 & 1 & 0.322 & 0.387 \\
\hline Separated & 3346 & 0.036 & 0.187 & 0 & 1 & 0.028 & 0.045 \\
\hline Divorced & 3346 & 0.024 & 0.152 & 0 & 1 & 0.017 & 0.030 \\
\hline Widowed & 3346 & 0.016 & 0.125 & 0 & 1 & 0.010 & 0.022 \\
\hline Married & 3346 & 0.570 & 0.495 & 0 & 1 & 0.541 & 0.599 \\
\hline
\end{tabular}


Table 2 - Life satisfaction and preferences for economic well-being vs. social relations

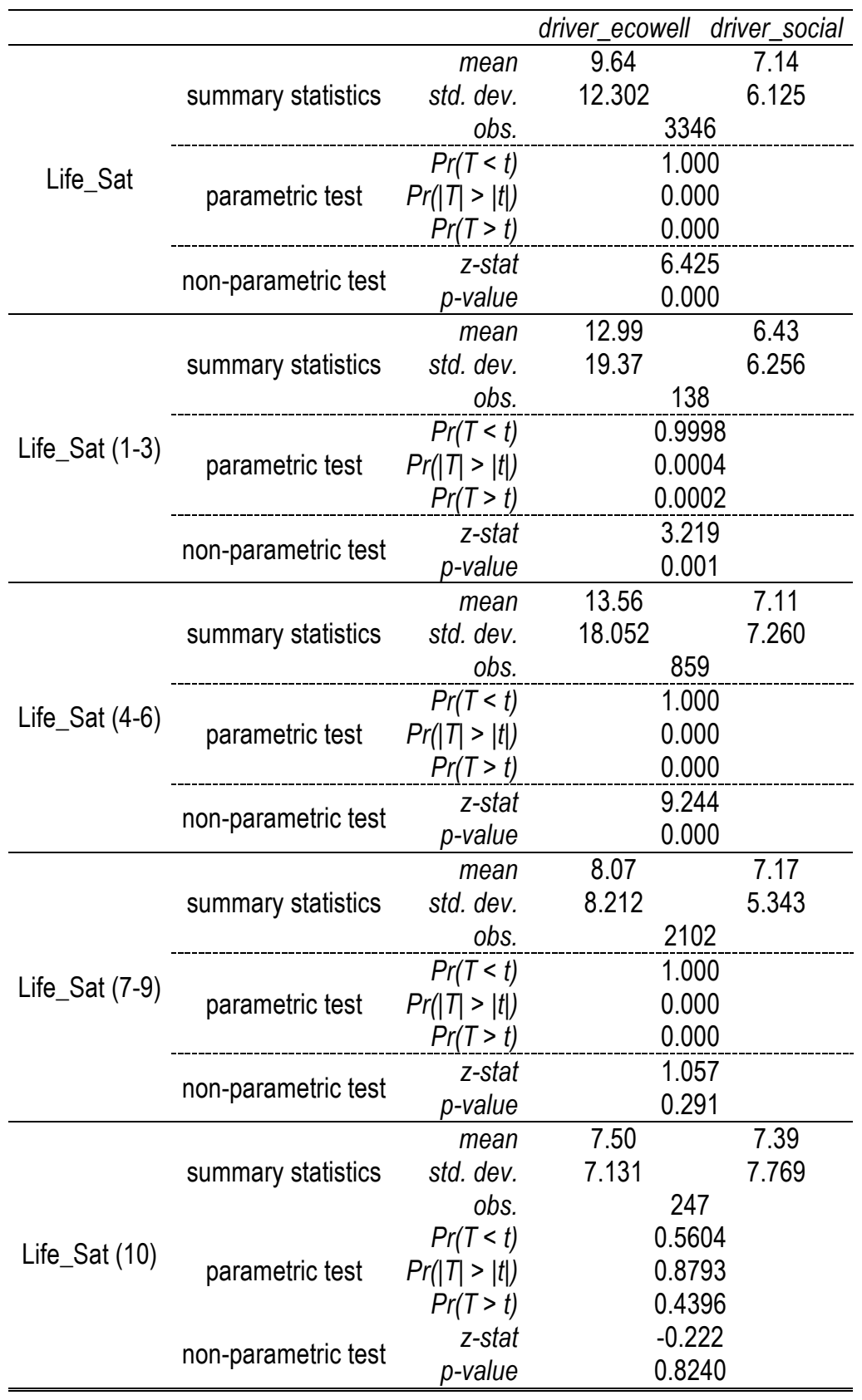


Table 3 - Life satisfaction and well-being domains: ordered logit regressions

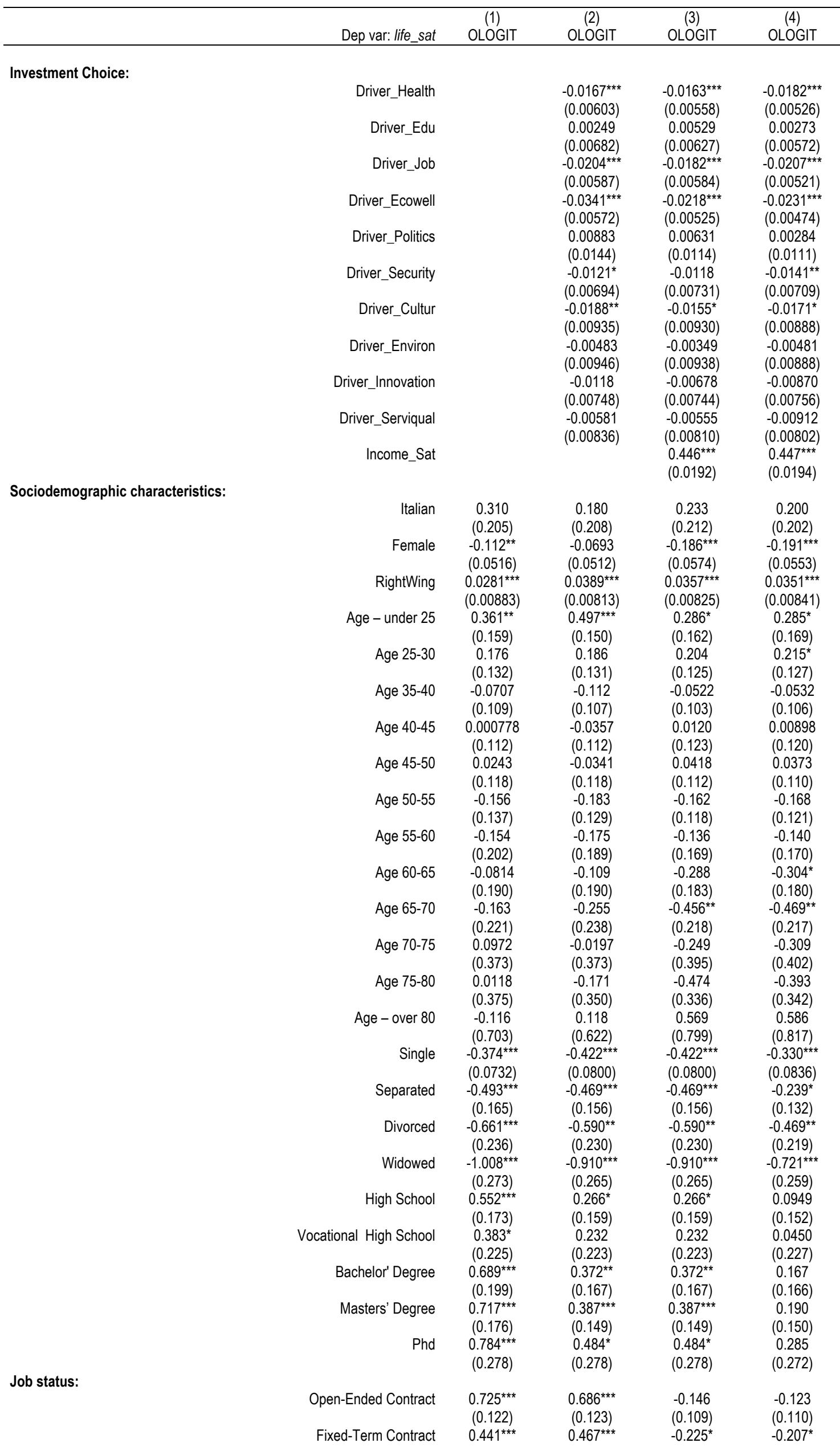




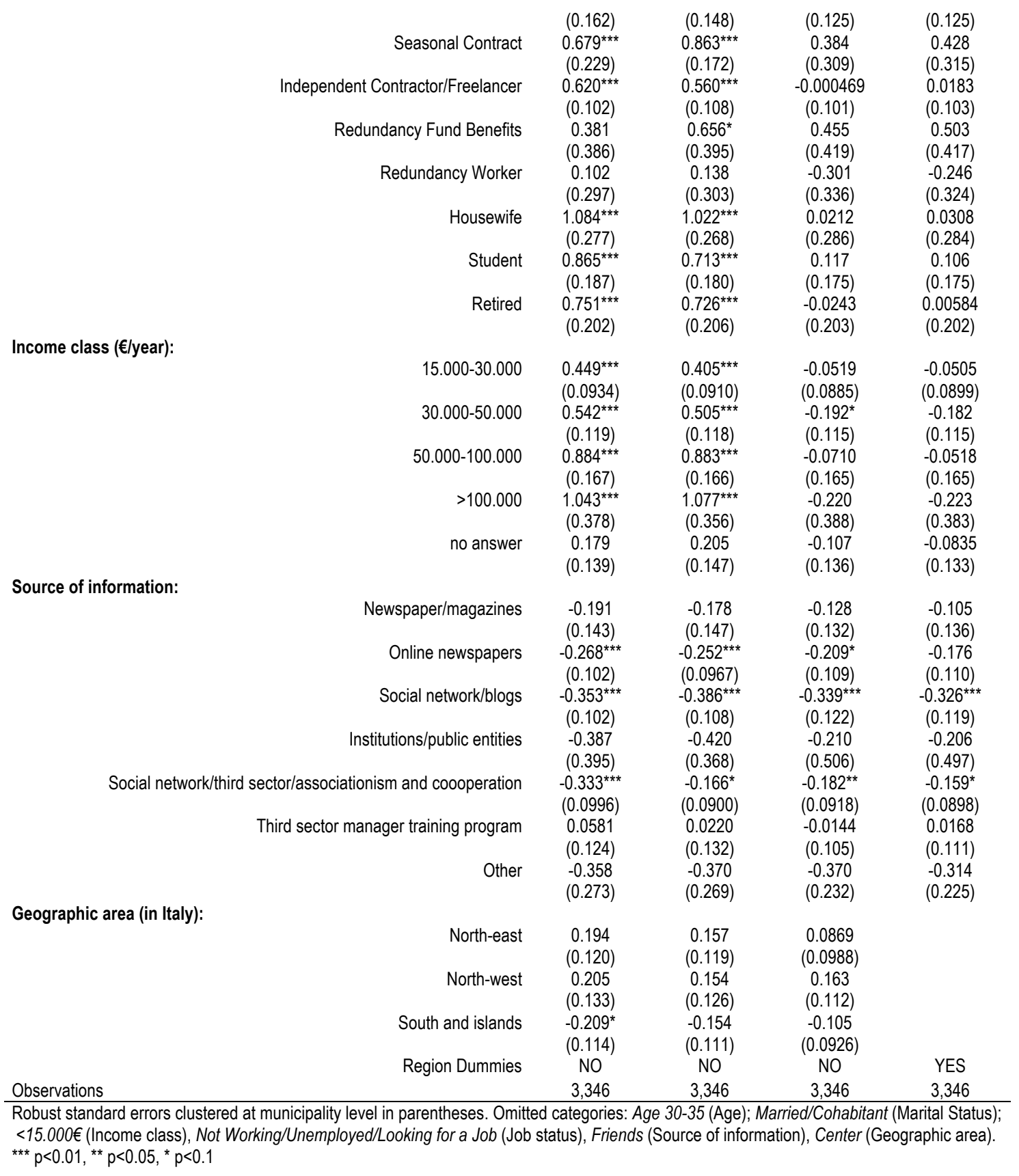


Table 4 - Tackling endogeneity

\begin{tabular}{|c|c|c|c|c|c|c|c|c|c|c|}
\hline \multirow[b]{3}{*}{ dep var: } & (1) & (2) & (3) & (4) & \multirow{2}{*}{\multicolumn{2}{|c|}{ IV }} & \multirow{3}{*}{$\begin{array}{c}(7) \\
\text { OPROBIT } \\
\text { life_sat }\end{array}$} & \multirow{3}{*}{$\begin{array}{c}\text { (8) } \\
\text { TOBIT } \\
\text { driver_ecowell }\end{array}$} & \multirow{3}{*}{$\begin{array}{c}\text { (9) } \\
\text { TOBIT } \\
\text { ratio_LS }\end{array}$} & (10) \\
\hline & \multicolumn{4}{|c|}{ OLS } & & & & & & TOBIT \\
\hline & life_sat & ratio_LS & life_sat & ratio_LS & life_sat & ratio_LS & & & & ratio_EW \\
\hline driver_ecowell & $-0.013^{* * *}$ & & $-0.012^{* * *}$ & & $-0.015^{\star * *}$ & & $-0.0269^{* * *}$ & & & \\
\hline & $(0.0026)$ & & $(0.0029)$ & & $(0.0050)$ & & $(0.00850)$ & & & \\
\hline income_sat & $\begin{array}{l}0.360^{* * *} \\
(0.0160)\end{array}$ & & $\begin{array}{l}0.360^{* * *} \\
(0.0160)\end{array}$ & & $\begin{array}{l}0.359^{* * *} \\
(0.0158)\end{array}$ & & $\begin{array}{l}0.225^{\star \star *} \\
(0.0138)\end{array}$ & $\begin{array}{c}-0.709^{* * *} \\
(0.165)\end{array}$ & & \\
\hline ratio_IS & & $0.271^{* * *}$ & & $0.271^{* * *}$ & & $0.269^{* * *}$ & & & $0.237^{* * *}$ & $-0.345^{\star \star \star}$ \\
\hline & & $(0.0142)$ & & $(0.0142)$ & & $(0.0122)$ & & & $(0.0215)$ & $(0.0458)$ \\
\hline ratio_EW & & $-0.018^{* * *}$ & & $-0.015^{\star *}$ & & $-0.022^{\star * *}$ & & & $-0.127^{\star \star \star}$ & \\
\hline & & $(0.0058)$ & & $(0.0066)$ & & $(0.0073)$ & & & $(0.0446)$ & \\
\hline mean_EW & & & 0.202 & 0.050 & & & & $0.769^{* * *}$ & & -0.00799 \\
\hline & & & (0.3894) & $(0.0647)$ & & & & $(0.143)$ & & $(0.00626)$ \\
\hline Sociodemographic characteristics & & & & & & & & & & \\
\hline italian & 0.206 & 0.037 & 0.206 & 0.037 & 0.193 & 0.036 & -0.0168 & $-5.842^{*}$ & 0.0178 & -0.165 \\
\hline & $(0.1723)$ & $(0.0246)$ & $(0.1721)$ & $(0.0244)$ & $(0.2065)$ & $(0.0298)$ & $(0.129)$ & (3.164) & $(0.0284)$ & $(0.149)$ \\
\hline female & $-0.142^{* * *}$ & $-0.020^{* * *}$ & $-0.142^{* * *}$ & $-0.020^{* * *}$ & $-0.139^{\star *}$ & $-0.020^{\star \star}$ & $-0.0694^{* *}$ & $1.899^{* * *}$ & -0.00790 & $0.139^{* * *}$ \\
\hline & $(0.0510)$ & $(0.0071)$ & $(0.0510)$ & $(0.0071)$ & $(0.0585)$ & $(0.0082)$ & $(0.0352)$ & $(0.647)$ & $(0.00879)$ & $(0.0497)$ \\
\hline RightWing & $0.028^{* * *}$ & $0.004^{* * *}$ & $0.028^{* * *}$ & $0.004^{* * *}$ & $0.029^{* * *}$ & $0.004^{* * *}$ & $0.0245^{\star * *}$ & $0.370^{* * *}$ & $0.00633^{* * *}$ & $0.0269^{* * *}$ \\
\hline & $(0.0062)$ & $(0.0009)$ & $(0.0062)$ & $(0.0009)$ & $(0.0064)$ & $(0.0009)$ & $(0.00488)$ & $(0.113)$ & $(0.00137)$ & $(0.00511)$ \\
\hline Age - under 25 & $0.253^{*}$ & 0.032 & $0.251^{*}$ & 0.032 & $0.263^{*}$ & 0.033 & $0.244^{* *}$ & $5.213^{* * *}$ & $0.0591^{* *}$ & $0.272^{\star \star \star}$ \\
\hline & $(0.1473)$ & $(0.0205)$ & $(0.1476)$ & $(0.0205)$ & $(0.1504)$ & $(0.0212)$ & $(0.106)$ & $(1.776)$ & $(0.0249)$ & $(0.0757)$ \\
\hline Age $25-30$ & 0.116 & 0.015 & 0.115 & 0.015 & 0.116 & 0.015 & 0.0861 & 0.460 & 0.0189 & 0.0523 \\
\hline & $(0.1299)$ & $(0.0185)$ & $(0.1300)$ & $(0.0185)$ & $(0.1192)$ & $(0.0169)$ & $(0.0737)$ & (0.591) & $(0.0171)$ & $(0.0585)$ \\
\hline Age $35-40$ & -0.022 & -0.003 & -0.023 & -0.003 & -0.023 & -0.003 & -0.0148 & -0.823 & -0.00220 & -0.0144 \\
\hline & $(0.0861)$ & $(0.0121)$ & $(0.0861)$ & $(0.0121)$ & $(0.1087)$ & $(0.0153)$ & $(0.0580)$ & $(0.996)$ & $(0.0124)$ & $(0.0805)$ \\
\hline Age $40-45$ & -0.004 & -0.001 & -0.003 & -0.001 & -0.007 & -0.001 & -0.0233 & $-2.075^{\star *}$ & -0.0116 & $-0.137^{*}$ \\
\hline & $(0.0989)$ & $(0.0139)$ & (0.0991) & $(0.0139)$ & $(0.1095)$ & $(0.0155)$ & $(0.0693)$ & $(0.964)$ & $(0.0159)$ & $(0.0740)$ \\
\hline Age 45-50 & 0.029 & 0.002 & 0.028 & 0.002 & 0.025 & 0.001 & 0.00992 & $-2.443^{\star *}$ & -0.0159 & $-0.208^{\star *}$ \\
\hline & $(0.0894)$ & $(0.0124)$ & $(0.0894)$ & $(0.0124)$ & $(0.1135)$ & $(0.0159)$ & $(0.0631)$ & $(0.998)$ & $(0.0157)$ & $(0.0897)$ \\
\hline Age $50-55$ & -0.136 & -0.020 & -0.137 & -0.020 & -0.140 & -0.021 & $-0.119^{*}$ & $-2.201^{* *}$ & $-0.0359^{* *}$ & $-0.181^{\star *}$ \\
\hline & $(0.1041)$ & $(0.0147)$ & (0.1041) & $(0.0147)$ & $(0.1188)$ & $(0.0167)$ & $(0.0700)$ & $(0.950)$ & $(0.0164)$ & $(0.0778)$ \\
\hline Age $55-60$ & -0.185 & -0.028 & -0.185 & -0.028 & -0.187 & -0.029 & -0.107 & -1.725 & $-0.0370^{*}$ & -0.126 \\
\hline & $(0.1686)$ & $(0.0235)$ & $(0.1687)$ & $(0.0235)$ & $(0.1368)$ & $(0.0191)$ & $(0.100)$ & $(1.184)$ & $(0.0214)$ & $(0.106)$ \\
\hline Age $60-65$ & -0.223 & -0.032 & -0.222 & -0.032 & -0.227 & -0.033 & $-0.207^{* *}$ & $-2.649^{* *}$ & $-0.0474^{* *}$ & $-0.196^{*}$ \\
\hline & $(0.1515)$ & $(0.0209)$ & $(0.1514)$ & $(0.0208)$ & $(0.1495)$ & $(0.0209)$ & $(0.103)$ & $(1.329)$ & $(0.0219)$ & $(0.116)$ \\
\hline Age $65-70$ & $-0.447^{\star *}$ & $-0.061^{* *}$ & $-0.446^{\star \star}$ & $-0.061^{* *}$ & $-0.453^{\star *}$ & $-0.062^{* *}$ & $-0.319^{* *}$ & $-3.598^{*}$ & $-0.0799^{* * *}$ & $-0.226^{\star}$ \\
\hline & $(0.1959)$ & $(0.0269)$ & $(0.1959)$ & $(0.0269)$ & $(0.1896)$ & $(0.0266)$ & $(0.141)$ & $(1.884)$ & $(0.0309)$ & $(0.137)$ \\
\hline Age $70-75$ & -0.246 & -0.028 & -0.246 & -0.028 & -0.257 & -0.030 & -0.251 & $-6.401^{* \star *}$ & $-0.0688^{*}$ & $-0.450^{* * *}$ \\
\hline & $(0.3265)$ & $(0.0458)$ & $(0.3266)$ & $(0.0459)$ & $(0.2391)$ & $(0.0336)$ & $(0.212)$ & $(2.244)$ & $(0.0369)$ & $(0.169)$ \\
\hline Age $75-80$ & -0.075 & -0.003 & -0.078 & -0.004 & -0.084 & -0.004 & -0.246 & $-4.955^{\star}$ & -0.0256 & -0.259 \\
\hline & $(0.3427)$ & $(0.0528)$ & $(0.3434)$ & $(0.0529)$ & $(0.3154)$ & $(0.0479)$ & $(0.202)$ & $(2.845)$ & $(0.0451)$ & $(0.204)$ \\
\hline Age - over 80 & 0.108 & 0.019 & 0.107 & 0.018 & 0.098 & 0.018 & 0.0929 & -6.387 & 0.00116 & -0.284 \\
\hline & $(0.7863)$ & $(0.1124)$ & $(0.7860)$ & $(0.1125)$ & $(0.7926)$ & $(0.1112)$ & $(0.406)$ & (5.508) & $(0.0881)$ & $(0.547)$ \\
\hline single & $-0.252^{* * *}$ & $-0.034^{* * *}$ & $-0.252^{* * *}$ & $-0.034^{* * *}$ & $-0.255^{* * *}$ & $-0.034^{* * *}$ & $-0.208^{* * *}$ & $-1.316^{*}$ & $-0.0375^{\star * *}$ & -0.0410 \\
\hline & $(0.0728)$ & $(0.0100)$ & $(0.0730)$ & $(0.0100)$ & $(0.0714)$ & $(0.0100)$ & $(0.0511)$ & $(0.691)$ & $(0.0118)$ & $(0.0558)$ \\
\hline separated & -0.216 & -0.030 & -0.216 & -0.030 & -0.217 & -0.030 & $-0.159^{*}$ & -0.299 & -0.0302 & -0.00901 \\
\hline & $(0.1327)$ & $(0.0183)$ & $(0.1327)$ & $(0.0183)$ & $(0.1493)$ & $(0.0209)$ & $(0.0865)$ & $(1.013)$ & $(0.0196)$ & $(0.0849)$ \\
\hline divorced & $-0.437^{\star *}$ & $-0.063^{* *}$ & $-0.436^{\star *}$ & $-0.063^{* \star}$ & $-0.438^{\star *}$ & $-0.063^{\star *}$ & $-0.295^{\star \star}$ & -0.276 & $-0.0635^{\star *}$ & -0.0276 \\
\hline & $(0.2037)$ & $(0.0279)$ & $(0.2043)$ & $(0.0280)$ & $(0.1770)$ & $(0.0249)$ & $(0.117)$ & $(1.400)$ & $(0.0268)$ & $(0.125)$ \\
\hline widowed & $-0.879^{* * *}$ & $-0.129^{* * *}$ & $-0.878^{* * *}$ & $-0.129^{* \star *}$ & $-0.876^{\star * *}$ & $-0.128^{* * *}$ & $-0.506^{* \star *}$ & 1.934 & $-0.108^{* *}$ & $0.247^{*}$ \\
\hline & $(0.2829)$ & $(0.0410)$ & $(0.2832)$ & $(0.0411)$ & $(0.2767)$ & $(0.0401)$ & $(0.168)$ & $(1.853)$ & $(0.0461)$ & $(0.144)$ \\
\hline high school & $0.227^{*}$ & $0.038^{* *}$ & $0.227^{*}$ & $0.037^{\star \star}$ & 0.214 & $0.037^{\star *}$ & -0.00157 & $-5.709^{* *}$ & 0.0122 & $-0.213^{*}$ \\
\hline & $(0.1260)$ & $(0.0173)$ & $(0.1259)$ & $(0.0174)$ & $(0.1324)$ & $(0.0182)$ & $(0.0950)$ & $(2.478)$ & $(0.0219)$ & $(0.115)$ \\
\hline vocational high school & 0.227 & 0.034 & 0.224 & 0.033 & 0.223 & 0.033 & 0.0930 & -1.348 & 0.0239 & -0.0651 \\
\hline & $(0.2123)$ & $(0.0296)$ & $(0.2132)$ & $(0.0298)$ & $(0.1935)$ & $(0.0274)$ & $(0.135)$ & $(1.627)$ & $(0.0323)$ & $(0.148)$ \\
\hline bachelor' degree & $0.338^{* *}$ & $0.055^{\star * *}$ & $0.338^{* *}$ & $0.054^{* * *}$ & $0.324^{\star *}$ & $0.053^{* * *}$ & 0.0516 & $-6.405^{\star *}$ & 0.0241 & $-0.258^{* *}$ \\
\hline & $(0.1346)$ & $(0.0192)$ & $(0.1347)$ & $(0.0193)$ & $(0.1467)$ & $(0.0201)$ & $(0.0926)$ & $(2.864)$ & $(0.0199)$ & $(0.127)$ \\
\hline masters' degree & $0.312^{* * *}$ & $0.050^{* * *}$ & $0.312^{* * *}$ & $0.049^{* * *}$ & $0.298^{* *}$ & $0.048^{* *}$ & 0.0282 & $-6.781^{* *}$ & 0.0158 & $-0.293^{* *}$ \\
\hline & $(0.1174)$ & $(0.0160)$ & $(0.1174)$ & $(0.0161)$ & $(0.1385)$ & $(0.0189)$ & $(0.101)$ & $(2.893)$ & $(0.0235)$ & $(0.131)$ \\
\hline phd & 0.329 & 0.051 & 0.327 & 0.051 & 0.317 & $0.050^{*}$ & 0.0812 & $-5.245^{\star *}$ & 0.0232 & $-0.239^{*}$ \\
\hline & $(0.2283)$ & $(0.0315)$ & $(0.2286)$ & $(0.0315)$ & $(0.2159)$ & $(0.0298)$ & -0.0168 & $-5.842^{*}$ & 0.0178 & -0.165 \\
\hline & & & & & & & & & & \\
\hline open-ended contract & -0.023 & -0.002 & -0.024 & -0.003 & -0.023 & -0.002 & -0.0594 & 0.321 & 0.00605 & 0.0832 \\
\hline & $(0.1015)$ & $(0.0142)$ & $(0.1013)$ & $(0.0142)$ & $(0.1015)$ & $(0.0142)$ & $(0.0646)$ & $(0.782)$ & $(0.0150)$ & $(0.0747)$ \\
\hline fixed-term contract & -0.090 & -0.014 & -0.090 & -0.014 & -0.090 & -0.014 & -0.0930 & $1.779^{*}$ & -0.00192 & $0.140^{*}$ \\
\hline & $(0.1234)$ & $(0.0178)$ & $(0.1235)$ & $(0.0178)$ & $(0.1234)$ & $(0.0178)$ & $(0.0701)$ & $(1.076)$ & $(0.0174)$ & $(0.0713)$ \\
\hline seasonal contract & $0.525^{\star \star}$ & 0.064 & $0.529^{* *}$ & $0.066^{*}$ & $0.525^{\star *}$ & 0.064 & $0.424^{* * *}$ & $7.490^{* * *}$ & $0.0965^{\star * *}$ & $0.320^{\star \star}$ \\
\hline & $(0.2577)$ & $(0.0390)$ & $(0.2598)$ & $(0.0392)$ & $(0.2577)$ & $(0.0390)$ & $(0.145)$ & $(2.798)$ & $(0.0295)$ & $(0.141)$ \\
\hline independent contractor/ & 0.130 & 0.019 & 0.130 & 0.019 & 0.130 & 0.019 & 0.0197 & -0.311 & 0.0225 & 0.0493 \\
\hline freelancer & $(0.0883)$ & $(0.0125)$ & $(0.0884)$ & $(0.0125)$ & $(0.0883)$ & $(0.0125)$ & $(0.0592)$ & $(0.920)$ & $(0.0143)$ & $(0.0813)$ \\
\hline redundancy fund & 0.516 & 0.067 & 0.515 & 0.068 & 0.516 & 0.067 & 0.424 & $10.15^{* * *}$ & $0.114^{* *}$ & $0.509^{\star *}$ \\
\hline benefits & $(0.3567)$ & $(0.0498)$ & $(0.3565)$ & $(0.0498)$ & $(0.3567)$ & $(0.0498)$ & $(0.265)$ & $(3.638)$ & $(0.0571)$ & $(0.210)$ \\
\hline & -0.188 & -0.028 & -0.189 & -0.028 & -0.188 & -0.028 & -0.169 & 0.359 & -0.0160 & 0.0955 \\
\hline redundancy worker & $(0.3041)$ & $(0.0423)$ & $(0.3042)$ & $(0.0424)$ & $(0.3041)$ & $(0.0423)$ & $(0.172)$ & (2.473) & $(0.0421)$ & $(0.270)$ \\
\hline housewife & 0.211 & 0.034 & 0.211 & 0.034 & 0.211 & 0.034 & 0.0959 & -1.193 & 0.0368 & 0.0415 \\
\hline & $(0.2404)$ & $(0.0349)$ & $(0.2405)$ & $(0.0349)$ & $(0.2404)$ & $(0.0349)$ & $(0.165)$ & (3.034) & $(0.0360)$ & $(0.217)$ \\
\hline student & 0.116 & 0.020 & 0.116 & 0.019 & 0.116 & 0.020 & -0.00648 & -3.338 & 0.0111 & -0.0715 \\
\hline
\end{tabular}




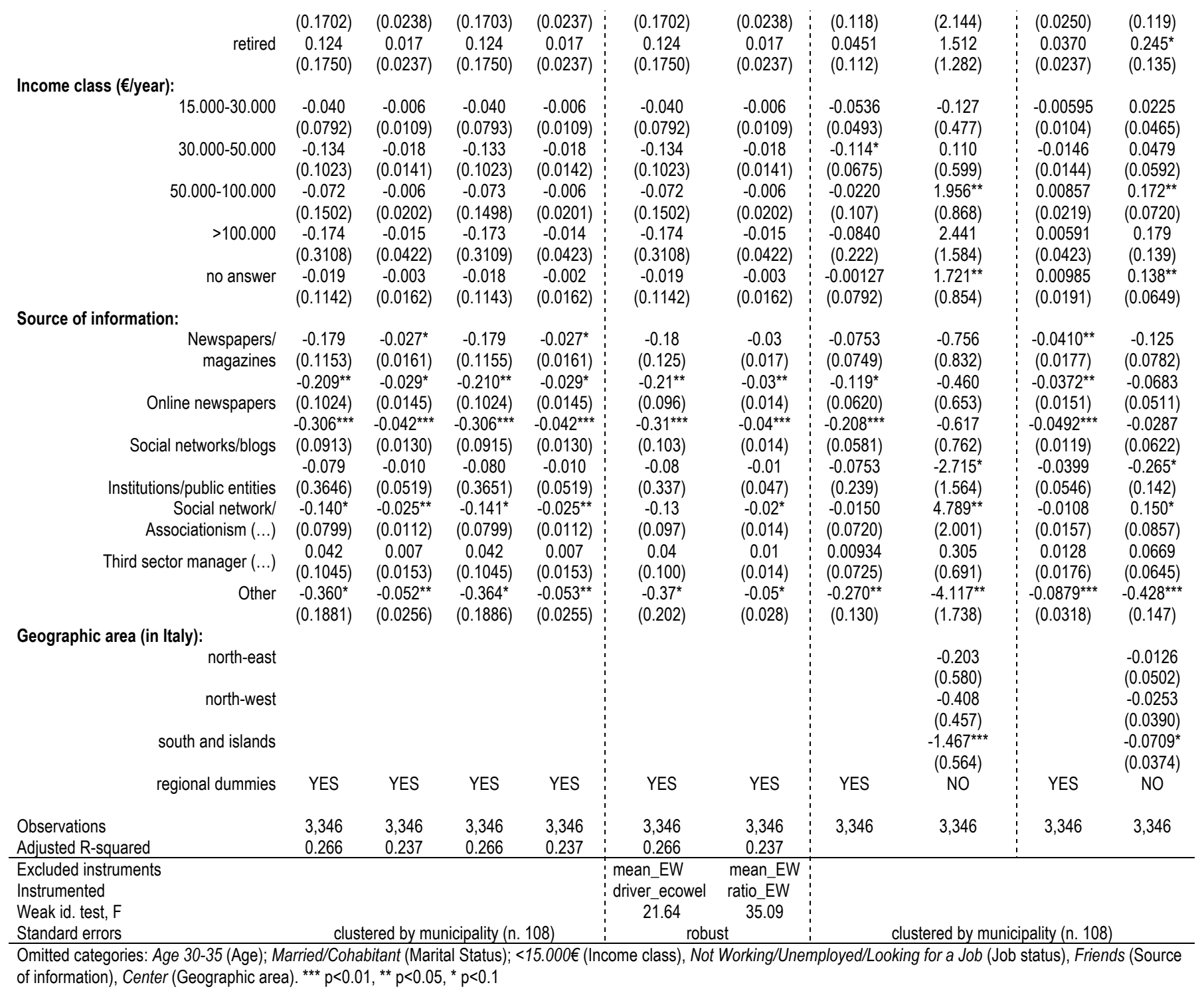


Table 5: economic well-being preferences and life satisfaction (heterogeneous effects - IV))

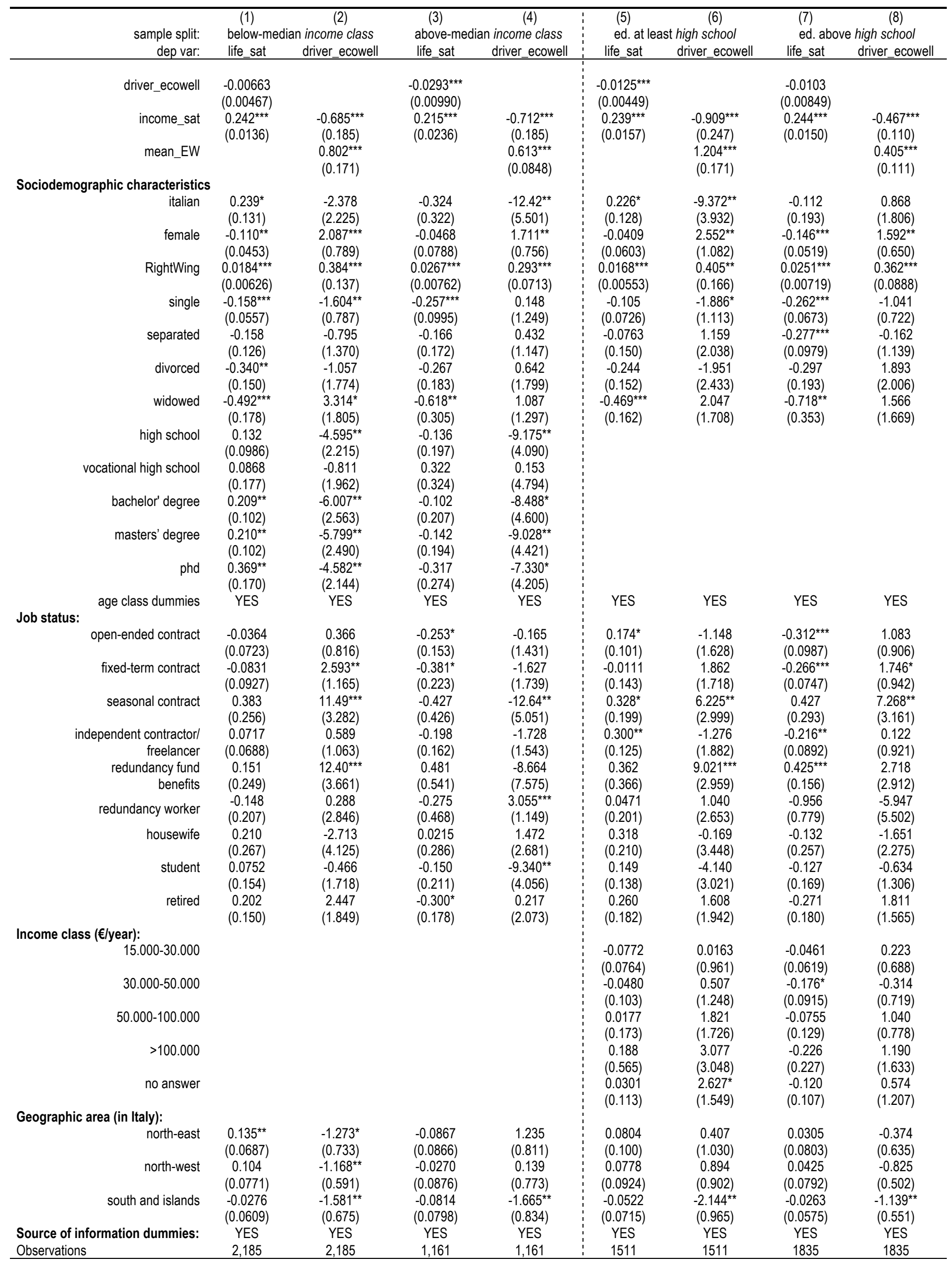


Figure 1 - Life satisfaction across well-being domains.

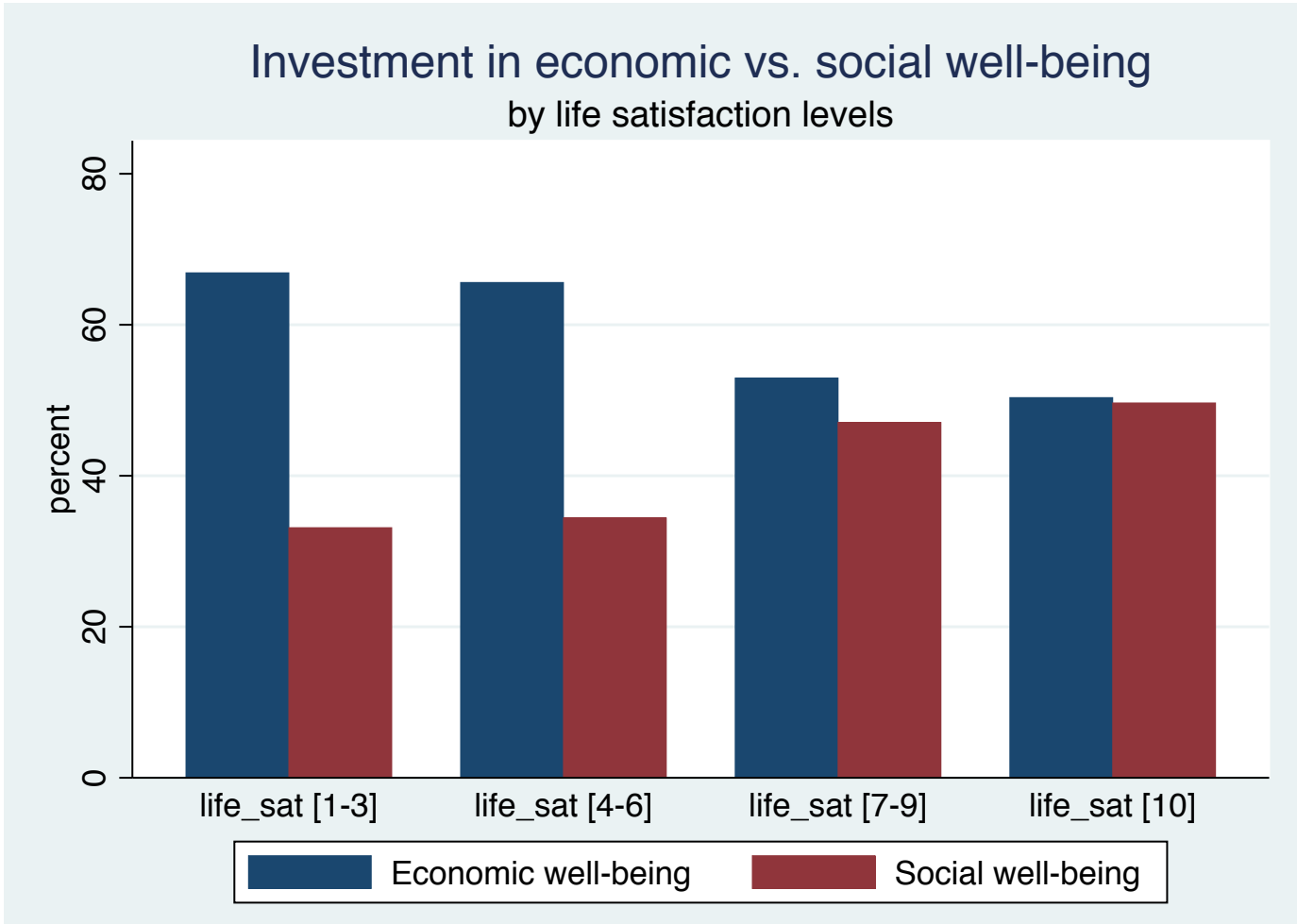

Figure 2 -Economic well-being investment vs. above-median life satisfaction

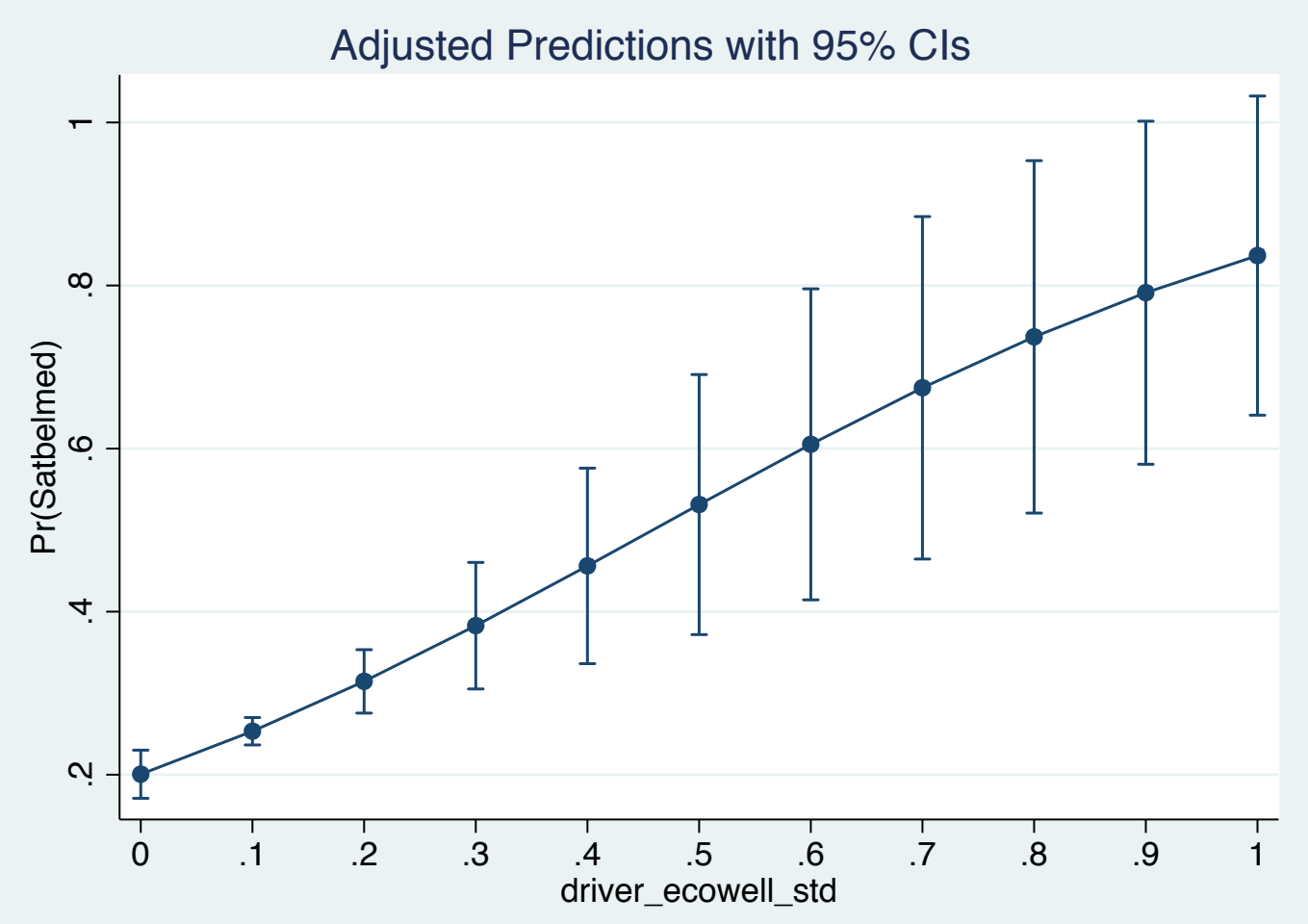

Note: The Figure reports marginal effects for unit-changes in the driver_ecowell/100 variable computed after estimating a logistic regression model in which the independent variables are those used in the specification in column 4 of Table 3 while the dependent variable (Satbelmed) is a dummy equal to one if life_sati<7 and 0 otherwise (seven is the sample median value of life_sat). 
Figure 3 - Life satisfaction and investment in economic well-being

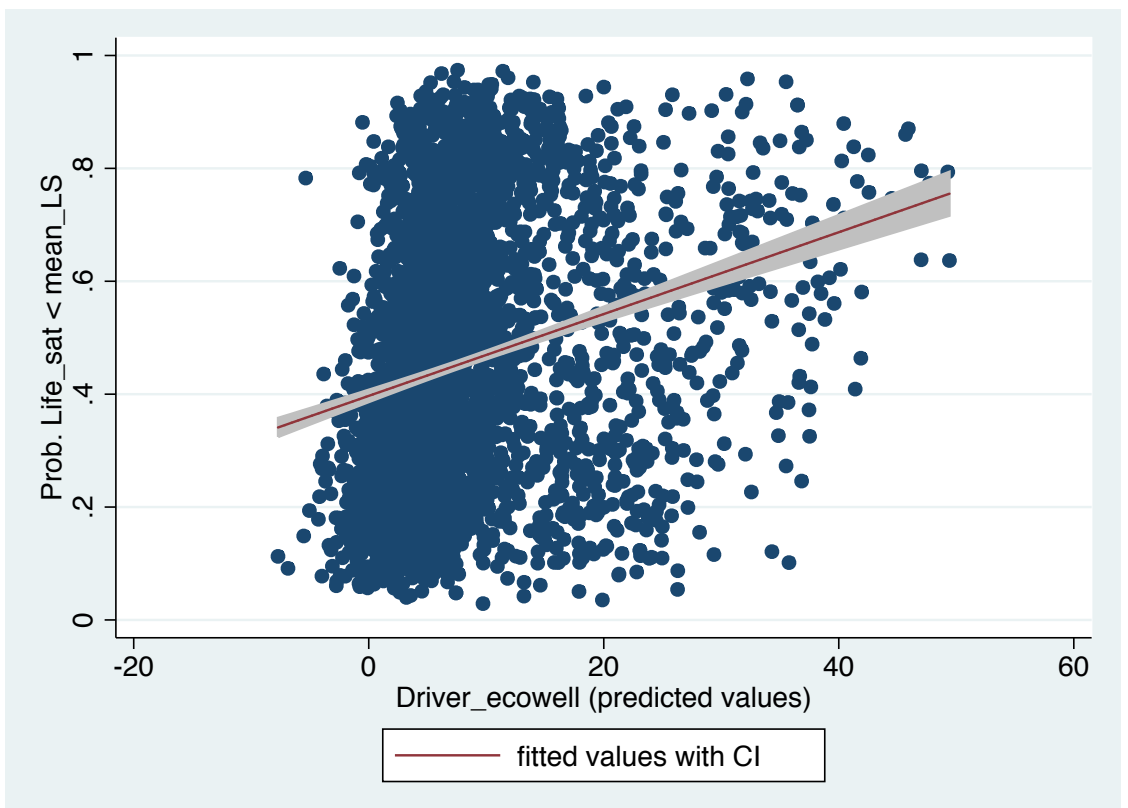

Notes: [1] Variable Prob. Life_sat < mean_LS (i.e. the prob. that the individual's life_sat is below the regional average life_sat) contains the predicted probabilities from a logistic regression of Prob. Life_sat < mean_LS on a set of socio-economic characteristics including civil status, income satisfaction, age, education, regional dummies, employment status, gender, nationality, income class, source of information (see Tables 3-4). [2] Variable Driver_ecowell contains the predicted probabilities from a logistic regression of the amount invested in economic well-being on the above-mentioned set of socio-economic characteristics. 
Figures 4-6 - Sensitivity Analysis

Figure 4

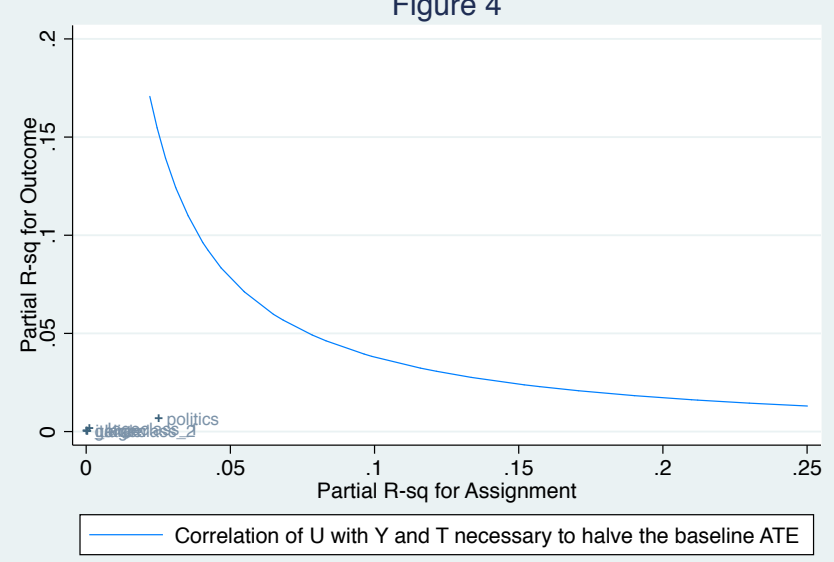

Figure 5

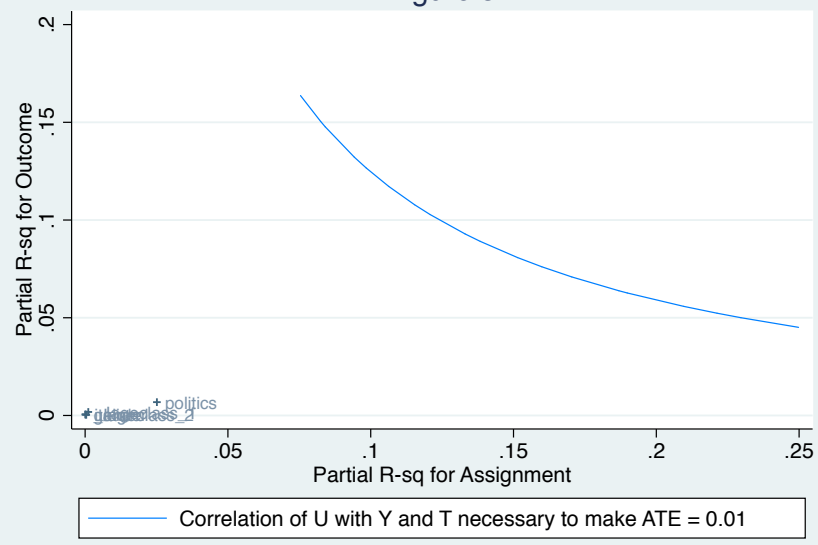

Figure 6

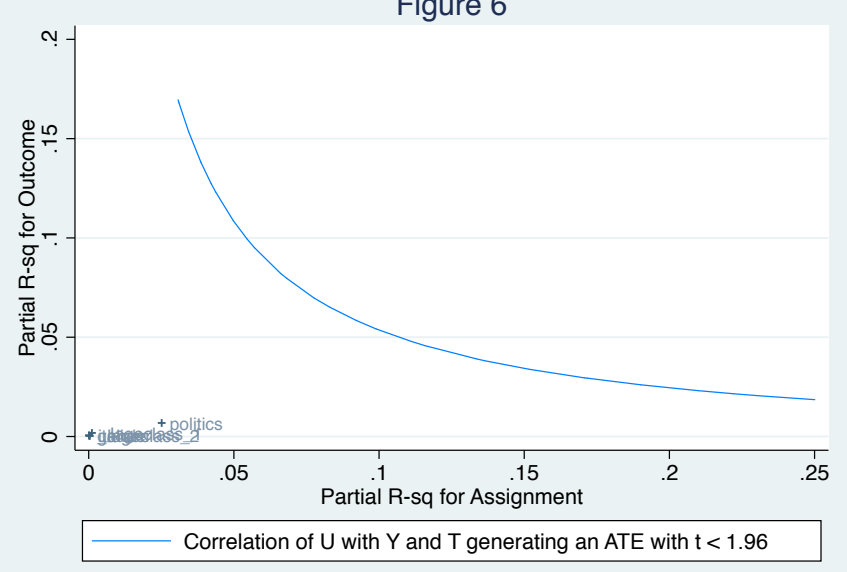

Notes: [1] We use the ISA program for the general sensitivity analysis (GSA) developed by Hamada (2012) which is built upon Imbens (2003)'s paper. The GSA does not hinge on the binary distributional assumption of $U$ as in Imbens (2003) while generating very similar results. [2] The "+" signs are the partial $R^{2}$ values for the $X$ covariates of the baseline model, plotted according to the additional explanatory power of the covariate for $T$ $\left(I_{\text {Driver_ecowell }}>\frac{\Sigma_{i} \text { Driver_ecowell }_{i}}{N}\right.$, horizontal axis) and for $\mathrm{Y}$ (life_sat, vertical axis); the axis measures variations in the $\mathrm{R}^{2}$ from adding that $\mathrm{X}$-regressor to the baseline model. [3] The solid curve is the set of partial $R^{2}$ for $U$ where the unobserved covariate correlated with both treatment and educational outcomes so to modify magnitude and/or significance of the baseline ATE. [4] In all estimations standard errors are clustered at municipality level. 


\section{Table A1 - Variable legend}

\author{
Variable \\ Life_sat \\ Income_sat \\ Driver_ecowell \\ Driver_health \\ Driver_edu \\ Driver_job \\ Driver_social \\ Driver_politics \\ Driver_security \\ Driver_cultur \\ Driver_environ \\ Driver_innovation \\ Driver_serviqual \\ Ratio_EW
}

Ratio_IS

Italian

Female

RightWing

Age class

North-East

North-West

South-and-Islands

Center

Open-Ended Contract

Fixed-Term Contract

Seasonal Contract

Independent Contractor/Freelancer

Redundancy Fund Benefits

Redundancy Worker

Housewife

Student

Retired

Not working

Income class: $<15$

Income class: $15-30$

Income class: $30-50$

Income class: 50-100

Income class: > 100

Income class: no answer

No school

Primary school

Middle school

High School

Vocational High School

Bachelor' Degree

Masters' Degree

\section{Description}

Self-declared degree of life satisfaction. Individual's answer on a 10-point Likert scale to the question "All in all, how much do you feel satisfied with regard to your overall life" [1=completely unsatisfied; $10=$ completely satisfied].

Self-declared degree of income satisfaction. Individual's answer on a 10-point Likert scale to the question "All in all, how much do you feel satisfied with regard to your economic conditions" [1=completely unsatisfied; $10=$ completely satisfied].

Amount invested in each of the 11 drivers (i.e., Economic well-being Health, Education and training, Work and life balance, Social relations, Politics and institutions, Safety, Landscape and cultural heritage, Environment, Research and innovation, Quality of service) when answering to the following question: Imagine you have the responsibility of government and you have an amount equal to 100 units (i.e. 100 million euro) to spend and you can decide how to distribute these resources among the various items making sure, however, the total sum destined is equal to one hundred.

Ratio between the individual-i's investment in the economic well-being driver and average sample investment on that domain in his/her region (the regional sample average has been calculated excluding his/her choice). In other terms, for each individual $i$ living in region $j$ we calculate the following ratio: ratio_E $W_{i, j}=\frac{\text { Driver_ecowell }_{i}}{\text { Mean_EW } W_{-i, j}}$, where Mean_EW $E W_{-i, j}=\frac{\sum_{j} \text { Driver_ecowell }_{-i, j}}{n_{j}-1}\left(n_{j}\right.$ is the total number of individuals in our sample who live in region $j$ ).

Ratio between the individual-i's self-declared level of income satisfaction and the average sample level of income satisfaction in his/her region (the regional sample average has been calculated excluding his/her choice). In other terms, for each individual $i$ living in region $j$ we calculate the following ratio: $r a t i o_{-} I S_{i, j}=$ $\frac{\text { Income_sat }}{\text { Mean_I } I S_{-i, j}}$, where Mean_IS $S_{-i, j}=\frac{\sum_{j} I n c o m e_{-} s a t_{-i, j}}{n_{j}-1}\left(n_{j}\right.$ is the total number of individuals in our sample who live in region $j$ ).

Dummy variable $=1$ if the respondent has an Italian citizenship and 0 otherwise.

Dummy variable $=1$ if the respondent's gender is female and 0 otherwise.

Respondent's political orientation expressed on a $-10 /+10$ scale ( -10 extreme left, +10 extreme right).

Set of age class dummies picking up five year age intervals starting from 25-30 and ending up with 75-80. Under 25 and Over 80 are two end classes also included as age dummies in the estimates, while the 30-35 age class is the omitted benchmark.

Dummy variable $=1$ if the respondent lives in the North Eastern Italian macro-area and 0 otherwise. Dummy variable $=1$ if the respondent lives in the North Western Italian macro-area and 0 otherwise. Dummy variable $=1$ if the respondent lives in the South and Islands Italian macro-area and 0 otherwise. Dummy variable $=1$ if the respondent lives in the Center Italian macro-area and 0 otherwise.

Dummy variable $=1$ if the respondent job status is Open-ended contract and 0 otherwise.

Dummy variable $=1$ if the respondent job status is Fixed-Term contract and 0 otherwise.

Dummy variable $=1$ if the respondent job status is Seasonal contract and 0 otherwise.

Dummy variable $=1$ if the respondent job status is Independent Contractor/Freelancer and 0 otherwise.

Dummy variable $=1$ if the respondent job status is Redundancy Fund Benefits and 0 otherwise.

Dummy variable $=1$ if the respondent job status is Redundancy Worker and 0 otherwise.

Dummy variable $=1$ if the respondent job status is Housewife and 0 otherwise.

Dummy variable $=1$ if the respondent job status is Student and 0 otherwise.

Dummy variable $=1$ if the respondent job status is Retired and 0 otherwise.

Dummy variable $=1$ if the respondent job status is Unemployed and 0 otherwise.

Dummy variable $=1$ if the respondent's income-class is Less than $€ 15.000$ per year and 0 otherwise.

Dummy variable $=1$ if the respondent's income-class is Between $€ 15.000$ and $€ 30.000$ per year and 0 otherwise.

Dummy variable $=1$ if the respondent's income-class is Between $€ 30.000$ and $€ 50.000$ per year and 0 otherwise.

Dummy variable $=1$ if the respondent's income-class is Between $€ 50.000$ and $€ 100.000$ per year and 0 otherwise.

Dummy variable $=1$ if the respondent's income-class is More than $€ 100.000$ per year and 0 otherwise.

Dummy variable $=1$ if the respondent's did not select any income-class option and 0 otherwise.

Dummy variable $=1$ if the respondent owns any education title and 0 otherwise.

Dummy variable $=1$ if the respondent owns a primary school title and 0 otherwise.

Dummy variable $=1$ if the respondent owns a middle school title and 0 otherwise.

Dummy variable $=1$ if the respondent owns a upper secondary high school title and 0 otherwise.

Dummy variable $=1$ if the respondent owns a technical vocational high school title (3 years) and 0 otherwise.

Dummy variable $=1$ if the respondent owns bachelor's degree title ( 3 years) and 0 otherwise.

Dummy variable $=1$ if the respondent owns masters' degree title ( 3 years) and 0 otherwise. 
Phd

Newspaper/magazines

Online newspapers

Social network/blogs

Institutions/public entities

Social network/third sector/associationism and coooperation

Third sector manager training program

Other

Friends

Single

Separated

Divorced

Widowed

Married
Dummy variable $=1$ if the respondent owns Phd title ( 3 years) and 0 otherwise.

Dummy variable $=1$ if the respondent heard about this research through newspaper/magazines and 0 otherwise.

Dummy variable $=1$ if the respondent heard about this research through online newspapers and 0 otherwise.

Dummy variable $=1$ if the respondent heard about this research through social network/blogs and 0 otherwise.

Dummy variable $=1$ if the respondent heard about this research through institutions/public entities and 0 otherwise.

Dummy variable $=1$ if the respondent heard about this research through Social network/third sector/Associationism and coooperation and 0 otherwise.

Dummy variable $=1$ if the respondent heard about this research through Third sector manager training program and 0 otherwise.

Dummy variable $=1$ if the respondent heard about this research through other sources and 0 otherwise.

Dummy variable $=1$ if the respondent heard about this research through acquaintances/friends and 0 otherwise.

Dummy variable $=1$ if the respondent's marital status is single and 0 otherwise.

Dummy variable $=1$ if the respondent's marital status is separated and 0 otherwise.

Dummy variable $=1$ if the respondent's marital status is divorced and 0 otherwise.

Dummy variable $=1$ if the respondent's marital status is widowed and 0 otherwise.

Dummy variable $=1$ if the respondent's marital status is married and 0 otherwise.

Table A2 - Life satisfaction and well-being domains: ordered logit regressions (sample balanced)

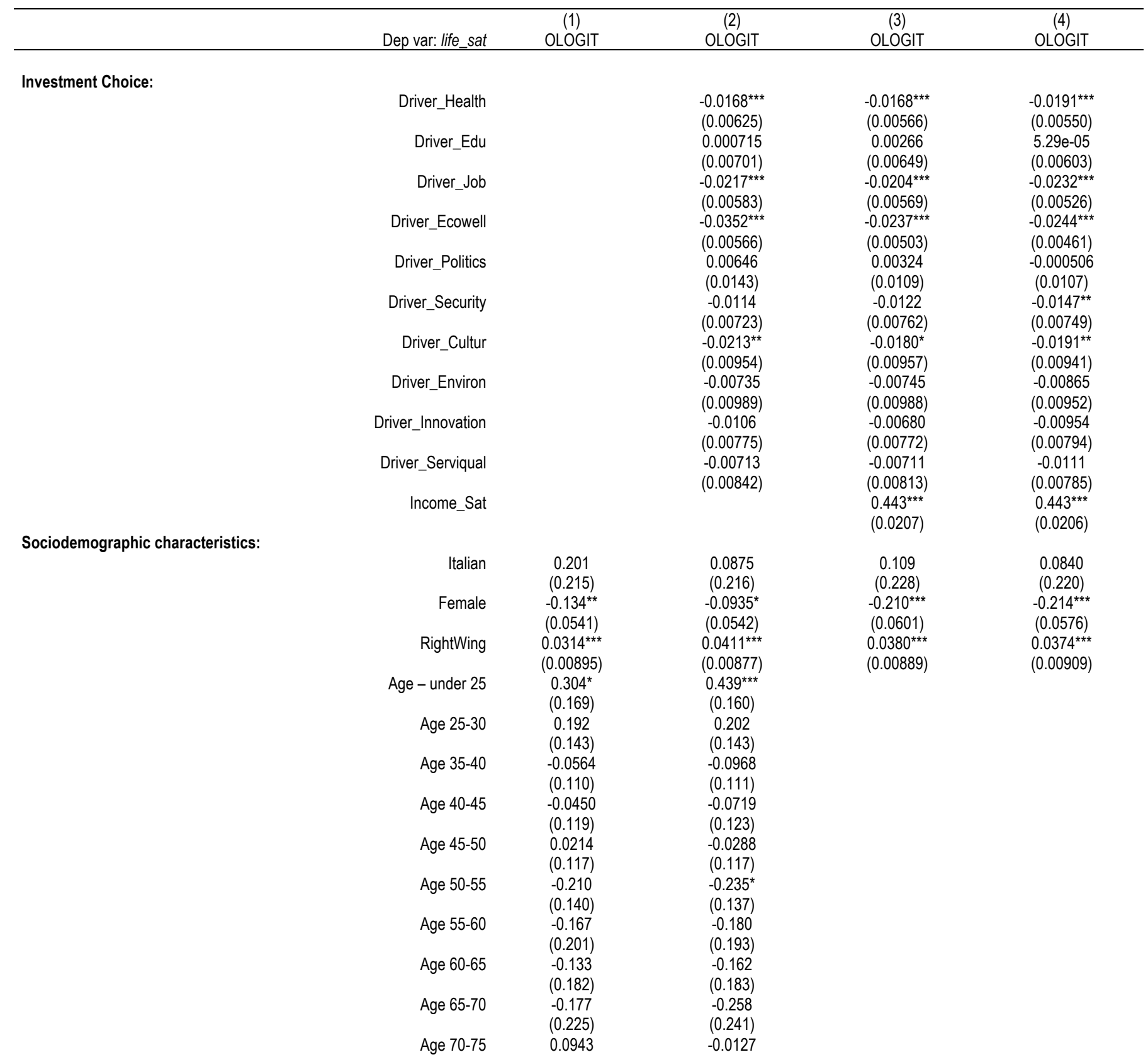




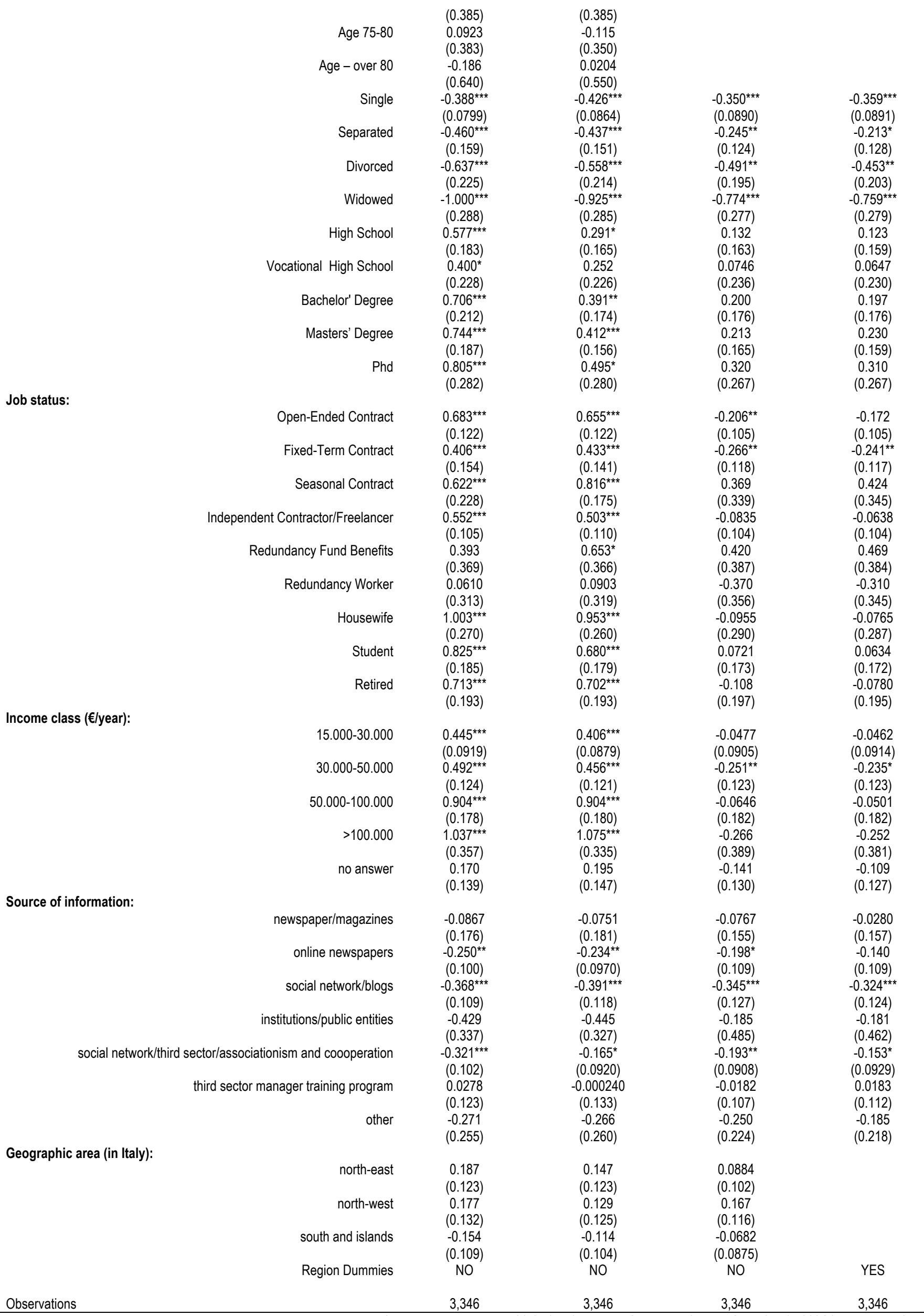

Robust standard errors clustered at municipality level in parentheses. Omitted categories: Age 30-35 (Age); Married/Cohabitant (Marital Status); $<15.000 €$ (Income class), Not Working/Unemployed/Looking for a Job (Job status), Friends (Source of information), Center (Geographic area). ${ }^{* * *} p<0.01,{ }^{* *} p<0.05,{ }^{*} p<0.1$ 
Table A3 - Tackling endogeneity (sample balanced)

\begin{tabular}{|c|c|c|c|c|c|c|c|c|c|c|}
\hline & (1) & (2) & (3) & (4) & (5) & (6) & \multirow{3}{*}{$\begin{array}{c}(7) \\
\text { OPROBIT } \\
\text { life_sat }\end{array}$} & \multirow{3}{*}{$\begin{array}{c}\text { (8) } \\
\text { TOBIT } \\
\text { driver_ecowell }\end{array}$} & \multirow{3}{*}{$\begin{array}{c}\text { (9) } \\
\text { TOBIT } \\
\text { ratio_LS }\end{array}$} & \multirow{3}{*}{$\begin{array}{c}(10) \\
\text { TOBIT } \\
\text { ratio_EW }\end{array}$} \\
\hline & \multicolumn{4}{|c|}{ OLS } & & & & & & \\
\hline dep var: & life_sat & ratio_LS & life_sat & ratio_LS & life_sat & ratio_LS & & & & \\
\hline driver_ecowell & $-0.012^{* * *}$ & & $-0.011^{* * *}$ & & $-0.014^{* * *}$ & & $-0.025^{\star * *}$ & & & \\
\hline & $(0.0024)$ & & $(0.0026)$ & & $(0.0050)$ & & $(0.0096)$ & & & \\
\hline income_sat & $\begin{array}{l}0.355^{\star * *} \\
(0.0168)\end{array}$ & & $\begin{array}{l}0.355^{* * *} \\
(0.0168)\end{array}$ & & $\begin{array}{l}0.353^{* * *} \\
(0.0163)\end{array}$ & & $\begin{array}{l}0.225^{\star * *} \\
(0.0145)\end{array}$ & $\begin{array}{l}-0.659^{\star * *} \\
(0.1431)\end{array}$ & & \\
\hline ratio_IS & & $0.265^{\star * *}$ & & $0.265^{\star * *}$ & & $0.264^{* * *}$ & & & $0.233^{* * *}$ & $-0.337^{\star * *}$ \\
\hline & & $(0.0148)$ & & $(0.0148)$ & & $(0.0127)$ & & & $(0.0215)$ & $(0.0418)$ \\
\hline ratio_EW & & $-0.017^{\star * *}$ & & $-0.015^{\star \star}$ & & $-0.021^{* * *}$ & & & $-0.125^{\star \star}$ & \\
\hline & & $(0.0053)$ & & $(0.0061)$ & & $(0.0072)$ & & & $(0.0503)$ & \\
\hline mean_EW & & & 0.225 & 0.044 & & & & $0.690^{* * *}$ & & $-0.011^{*}$ \\
\hline & & & $(0.3876)$ & $(0.0660)$ & & & & $(0.1427)$ & & $(0.0063)$ \\
\hline Sociodemographic characteristics & & & & & & & & & & \\
\hline italian & 0.131 & 0.025 & 0.131 & 0.025 & 0.119 & 0.024 & -0.045 & $-5.248^{*}$ & 0.007 & -0.159 \\
\hline & $(0.1850)$ & $(0.0265)$ & $(0.1850)$ & $(0.0264)$ & $(0.2110)$ & $(0.0304)$ & $(0.1363)$ & $(3.0828)$ & $(0.0308)$ & $(0.1492)$ \\
\hline female & $-0.146^{* * *}$ & $-0.021^{* * *}$ & $-0.146^{* * *}$ & $-0.021^{* * *}$ & $-0.143^{\star *}$ & $-0.021^{* *}$ & $-0.081^{* \star}$ & $1.792^{\star * \star}$ & -0.009 & $0.130^{* * *}$ \\
\hline & $(0.0530)$ & $(0.0074)$ & $(0.0530)$ & $(0.0074)$ & $(0.0595)$ & $(0.0084)$ & $(0.0391)$ & $(0.6310)$ & $(0.0099)$ & $(0.0483)$ \\
\hline RightWing & $0.030^{* * *}$ & $0.004^{* * *}$ & $0.030^{* * *}$ & $0.004^{* * *}$ & $0.031^{* * *}$ & $0.004^{* * *}$ & $0.026^{* * *}$ & $0.364^{* * *}$ & $0.007^{* * *}$ & $0.027^{* * *}$ \\
\hline & $(0.0067)$ & $(0.0009)$ & $(0.0068)$ & $(0.0009)$ & $(0.0064)$ & $(0.0009)$ & $(0.0053)$ & $(0.1074)$ & $(0.0015)$ & $(0.0049)$ \\
\hline Age - under 25 & 0.210 & 0.026 & 0.207 & 0.026 & 0.221 & 0.027 & $0.218^{* *}$ & $4.965^{\star * *}$ & $0.051^{\star *}$ & $0.251^{* * *}$ \\
\hline & $(0.1396)$ & $(0.0193)$ & $(0.1398)$ & $(0.0193)$ & $(0.1530)$ & $(0.0216)$ & $(0.1096)$ & (1.7679) & $(0.0256)$ & $(0.0753)$ \\
\hline Age $25-30$ & 0.120 & 0.015 & 0.120 & 0.015 & 0.120 & 0.015 & 0.094 & 0.325 & 0.018 & 0.039 \\
\hline & $(0.1347)$ & $(0.0192)$ & $(0.1348)$ & $(0.0193)$ & $(0.1221)$ & $(0.0174)$ & $(0.0779)$ & $(0.5995)$ & $(0.0176)$ & $(0.0601)$ \\
\hline Age $35-40$ & -0.009 & -0.001 & -0.010 & -0.001 & -0.011 & -0.001 & -0.007 & -1.168 & -0.004 & -0.061 \\
\hline & $(0.0915)$ & $(0.0128)$ & $(0.0914)$ & $(0.0128)$ & $(0.1095)$ & $(0.0154)$ & $(0.0636)$ & $(0.9438)$ & $(0.0138)$ & $(0.0783)$ \\
\hline Age $40-45$ & -0.022 & -0.003 & -0.021 & -0.003 & -0.026 & -0.004 & -0.032 & $-2.067^{\star *}$ & -0.015 & $-0.149^{*}$ \\
\hline & $(0.1104)$ & $(0.0156)$ & $(0.1105)$ & $(0.0156)$ & $(0.1117)$ & $(0.0158)$ & $(0.0782)$ & $(0.9375)$ & $(0.0186)$ & $(0.0791)$ \\
\hline Age $45-50$ & 0.036 & 0.003 & 0.036 & 0.003 & 0.032 & 0.002 & 0.022 & $-2.467^{\star *}$ & -0.016 & $-0.223^{* *}$ \\
\hline & $(0.0865)$ & $(0.0121)$ & $(0.0866)$ & $(0.0121)$ & $(0.1142)$ & $(0.0160)$ & $(0.0634)$ & $(0.9655)$ & $(0.0160)$ & $(0.0918)$ \\
\hline Age $50-55$ & -0.174 & $-0.026^{*}$ & -0.175 & $-0.026^{*}$ & -0.179 & -0.026 & $-0.142^{*}$ & $-2.449^{* * *}$ & $-0.045^{* *}$ & $-0.219^{* * *}$ \\
\hline & $(0.1057)$ & $(0.0149)$ & $(0.1056)$ & $(0.0149)$ & $(0.1208)$ & $(0.0170)$ & $(0.0744)$ & $(0.9331)$ & $(0.0181)$ & $(0.0848)$ \\
\hline Age $55-60$ & -0.170 & -0.027 & -0.171 & -0.027 & -0.174 & -0.027 & -0.102 & $-1.872^{*}$ & $-0.038^{*}$ & -0.152 \\
\hline & $(0.1683)$ & $(0.0234)$ & $(0.1684)$ & $(0.0234)$ & $(0.1343)$ & $(0.0187)$ & $(0.1018)$ & $(1.1326)$ & $(0.0207)$ & $(0.1033)$ \\
\hline Age $60-65$ & -0.246 & $-0.036^{*}$ & -0.246 & $-0.036^{*}$ & $-0.251^{*}$ & $-0.036^{*}$ & $-0.225^{\star \star}$ & $-2.814^{* \star}$ & $-0.054^{* *}$ & $-0.232^{* \star}$ \\
\hline & $(0.1503)$ & $(0.0207)$ & $(0.1503)$ & $(0.0207)$ & $(0.1463)$ & $(0.0205)$ & $(0.1047)$ & (1.2551) & $(0.0225)$ & $(0.1136)$ \\
\hline Age $65-70$ & $-0.432^{* *}$ & $-0.060^{* \star}$ & $-0.431^{* *}$ & $-0.060^{* *}$ & $-0.438^{* *}$ & $-0.060^{\star *}$ & $-0.303^{\star *}$ & $-3.563^{* *}$ & $-0.080^{* *}$ & $-0.240^{*}$ \\
\hline & $(0.1997)$ & $(0.0277)$ & (0.1997) & $(0.0277)$ & $(0.1891)$ & $(0.0266)$ & $(0.1443)$ & $(1.8002)$ & $(0.0329)$ & $(0.1337)$ \\
\hline Age $70-75$ & -0.213 & -0.024 & -0.214 & -0.024 & -0.226 & -0.026 & -0.215 & $-6.522^{* * *}$ & $-0.068^{*}$ & $-0.487^{* * *}$ \\
\hline & $(0.3402)$ & $(0.0474)$ & $(0.3403)$ & $(0.0475)$ & $(0.2456)$ & $(0.0345)$ & $(0.2229)$ & $(2.1707)$ & $(0.0372)$ & $(0.1724)$ \\
\hline Age $75-80$ & -0.022 & 0.002 & -0.025 & 0.002 & -0.031 & 0.001 & -0.204 & $-5.205^{*}$ & -0.026 & -0.325 \\
\hline & $(0.3295)$ & $(0.0500)$ & $(0.3300)$ & $(0.0501)$ & $(0.3004)$ & $(0.0450)$ & $(0.2024)$ & $(2.7070)$ & $(0.0439)$ & $(0.2128)$ \\
\hline Age - over 80 & 0.142 & 0.023 & 0.141 & 0.022 & 0.133 & 0.022 & 0.104 & -5.885 & 0.007 & -0.271 \\
\hline & $(0.7216)$ & $(0.1029)$ & $(0.7214)$ & $(0.1030)$ & $(0.7227)$ & $(0.1014)$ & $(0.3837)$ & $(5.3917)$ & $(0.0827)$ & $(0.5475)$ \\
\hline single & $-0.278^{* * *}$ & $-0.038^{* * *}$ & $-0.278^{* * *}$ & $-0.038^{* * *}$ & $-0.280^{* * *}$ & $-0.038^{* * *}$ & $-0.222^{* * *}$ & $-1.085^{*}$ & $-0.040^{* * *}$ & -0.026 \\
\hline & $(0.0814)$ & $(0.0113)$ & $(0.0815)$ & $(0.0113)$ & $(0.0742)$ & $(0.0104)$ & $(0.0543)$ & $(0.6379)$ & $(0.0127)$ & $(0.0520)$ \\
\hline separated & -0.198 & -0.028 & -0.198 & -0.028 & -0.198 & -0.028 & $-0.148^{*}$ & -0.168 & -0.026 & 0.009 \\
\hline & $(0.1282)$ & $(0.0178)$ & $(0.1282)$ & $(0.0178)$ & $(0.1516)$ & $(0.0213)$ & $(0.0826)$ & $(0.9362)$ & $(0.0183)$ & $(0.0823)$ \\
\hline divorced & $-0.418^{* *}$ & $-0.061^{* *}$ & $-0.417^{* *}$ & $-0.061^{* *}$ & $-0.417^{\star *}$ & $-0.061^{* *}$ & $-0.281^{* *}$ & 0.170 & $-0.058^{* *}$ & 0.002 \\
\hline & $(0.1973)$ & $(0.0268)$ & (0.1979) & $(0.0269)$ & $(0.1727)$ & $(0.0243)$ & $(0.1133)$ & (1.4747) & $(0.0248)$ & $(0.1276)$ \\
\hline widowed & $-0.915^{\star * *}$ & $-0.134^{* * *}$ & $-0.914^{* * *}$ & $-0.134^{* * *}$ & $-0.913^{\star * *}$ & $-0.133^{\star * *}$ & $-0.533^{\star * *}$ & 1.750 & $-0.115^{\star *}$ & $0.242^{*}$ \\
\hline & $(0.2964)$ & $(0.0431)$ & $(0.2966)$ & $(0.0431)$ & $(0.2972)$ & $(0.0433)$ & $(0.1758)$ & (1.9751) & $(0.0481)$ & $(0.1391)$ \\
\hline high school & $0.240^{*}$ & $0.039^{* *}$ & $0.240^{*}$ & $0.039^{* *}$ & $0.226^{*}$ & $0.038^{* *}$ & 0.005 & $-6.156^{* *}$ & 0.013 & $-0.231^{* *}$ \\
\hline & $(0.1286)$ & $(0.0178)$ & $(0.1285)$ & $(0.0178)$ & $(0.1329)$ & $(0.0182)$ & $(0.0982)$ & $(2.6151)$ & $(0.0228)$ & $(0.1175)$ \\
\hline vocational high school & 0.238 & 0.035 & 0.235 & 0.035 & 0.234 & 0.035 & 0.098 & -1.485 & 0.025 & -0.071 \\
\hline & $(0.2112)$ & $(0.0295)$ & $(0.2121)$ & $(0.0296)$ & $(0.1947)$ & $(0.0276)$ & $(0.1343)$ & $(1.6482)$ & $(0.0319)$ & $(0.1464)$ \\
\hline bachelor' degree & $0.355^{* *}$ & $0.057^{* * *}$ & $0.355^{\star *}$ & $0.056^{* * *}$ & $0.339^{* *}$ & $0.056^{* * *}$ & 0.062 & $-6.845^{\star *}$ & 0.025 & $-0.279^{* *}$ \\
\hline & $(0.1406)$ & $(0.0202)$ & $(0.1407)$ & $(0.0202)$ & $(0.1476)$ & $(0.0202)$ & $(0.1005)$ & $(2.9900)$ & $(0.0219)$ & $(0.1292)$ \\
\hline masters' degree & $0.338^{* * *}$ & $0.053^{* * *}$ & $0.337^{\star * *}$ & $0.053^{* * *}$ & $0.321^{* *}$ & $0.052^{* * *}$ & 0.041 & $-7.369^{* *}$ & 0.017 & $-0.321^{* *}$ \\
\hline & $(0.1204)$ & $(0.0165)$ & $(0.1204)$ & $(0.0166)$ & $(0.1393)$ & $(0.0190)$ & $(0.1093)$ & (3.0751) & $(0.0258)$ & $(0.1353)$ \\
\hline phd & 0.356 & $0.055^{*}$ & 0.354 & $0.055^{*}$ & 0.341 & $0.054^{*}$ & 0.087 & $-5.846^{* *}$ & 0.025 & $-0.254^{*}$ \\
\hline & $(0.2173)$ & $(0.0300)$ & $(0.2176)$ & $(0.0299)$ & $(0.2130)$ & $(0.0294)$ & $(0.1550)$ & $(2.5794)$ & $(0.0377)$ & $(0.1377)$ \\
\hline & & & & & & & & & & \\
\hline open-ended contract & -0.079 & -0.011 & -0.080 & -0.011 & -0.078 & -0.010 & -0.085 & 0.680 & 0.000 & 0.112 \\
\hline & $(0.1048)$ & $(0.0147)$ & $(0.1046)$ & $(0.0147)$ & $(0.1206)$ & $(0.0171)$ & $(0.0642)$ & $(0.7416)$ & $(0.0160)$ & $(0.0769)$ \\
\hline fixed-term contract & -0.123 & -0.018 & -0.123 & -0.018 & -0.120 & -0.018 & $-0.116^{*}$ & $1.732^{*}$ & -0.005 & $0.146^{* *}$ \\
\hline & $(0.1196)$ & $(0.0173)$ & $(0.1197)$ & $(0.0173)$ & $(0.1282)$ & $(0.0182)$ & $(0.0665)$ & $(0.9736)$ & $(0.0173)$ & $(0.0696)$ \\
\hline seasonal contract & $0.509^{*}$ & 0.062 & $0.511^{*}$ & 0.063 & $0.525^{\star *}$ & $0.063^{* *}$ & $0.409^{* * *}$ & $7.481^{* * *}$ & $0.093^{* * *}$ & $0.310^{* *}$ \\
\hline & $(0.2721)$ & $(0.0406)$ & $(0.2737)$ & $(0.0408)$ & $(0.2117)$ & $(0.0305)$ & $(0.1561)$ & $(2.7740)$ & $(0.0310)$ & $(0.1383)$ \\
\hline independent contractor/ & 0.053 & 0.007 & 0.053 & 0.007 & 0.053 & 0.008 & -0.021 & -0.006 & 0.013 & 0.069 \\
\hline freelancer & $(0.0913)$ & $(0.0130)$ & $(0.0914)$ & $(0.0130)$ & $(0.1231)$ & $(0.0175)$ & $(0.0587)$ & $(0.8455)$ & $(0.0153)$ & $(0.0806)$ \\
\hline redundancy fund & 0.469 & 0.061 & 0.467 & 0.061 & 0.490 & 0.063 & 0.386 & $10.180^{* * *}$ & $0.108^{* \star}$ & $0.515^{\star *}$ \\
\hline benefits & $(0.3333)$ & $(0.0465)$ & $(0.3330)$ & $(0.0465)$ & $(0.3377)$ & $(0.0483)$ & $(0.2484)$ & $(3.7777)$ & $(0.0533)$ & $(0.2149)$ \\
\hline & -0.262 & -0.038 & -0.263 & -0.039 & -0.261 & -0.038 & -0.206 & 0.213 & -0.028 & 0.080 \\
\hline redundancy worker & $(0.3282)$ & $(0.0459)$ & $(0.3283)$ & $(0.0460)$ & $(0.3290)$ & $(0.0467)$ & $(0.1862)$ & $(2.4421)$ & $(0.0460)$ & $(0.2689)$ \\
\hline housewife & 0.133 & 0.022 & 0.132 & 0.022 & 0.131 & 0.023 & 0.052 & -0.881 & 0.026 & 0.050 \\
\hline & $(0.2412)$ & $(0.0350)$ & $(0.2416)$ & $(0.0350)$ & $(0.2451)$ & $(0.0349)$ & $(0.1634)$ & $(2.7829)$ & $(0.0363)$ & $(0.2130)$ \\
\hline student & 0.099 & 0.017 & 0.099 & 0.017 & 0.092 & 0.017 & -0.014 & -3.148 & 0.009 & -0.066 \\
\hline
\end{tabular}




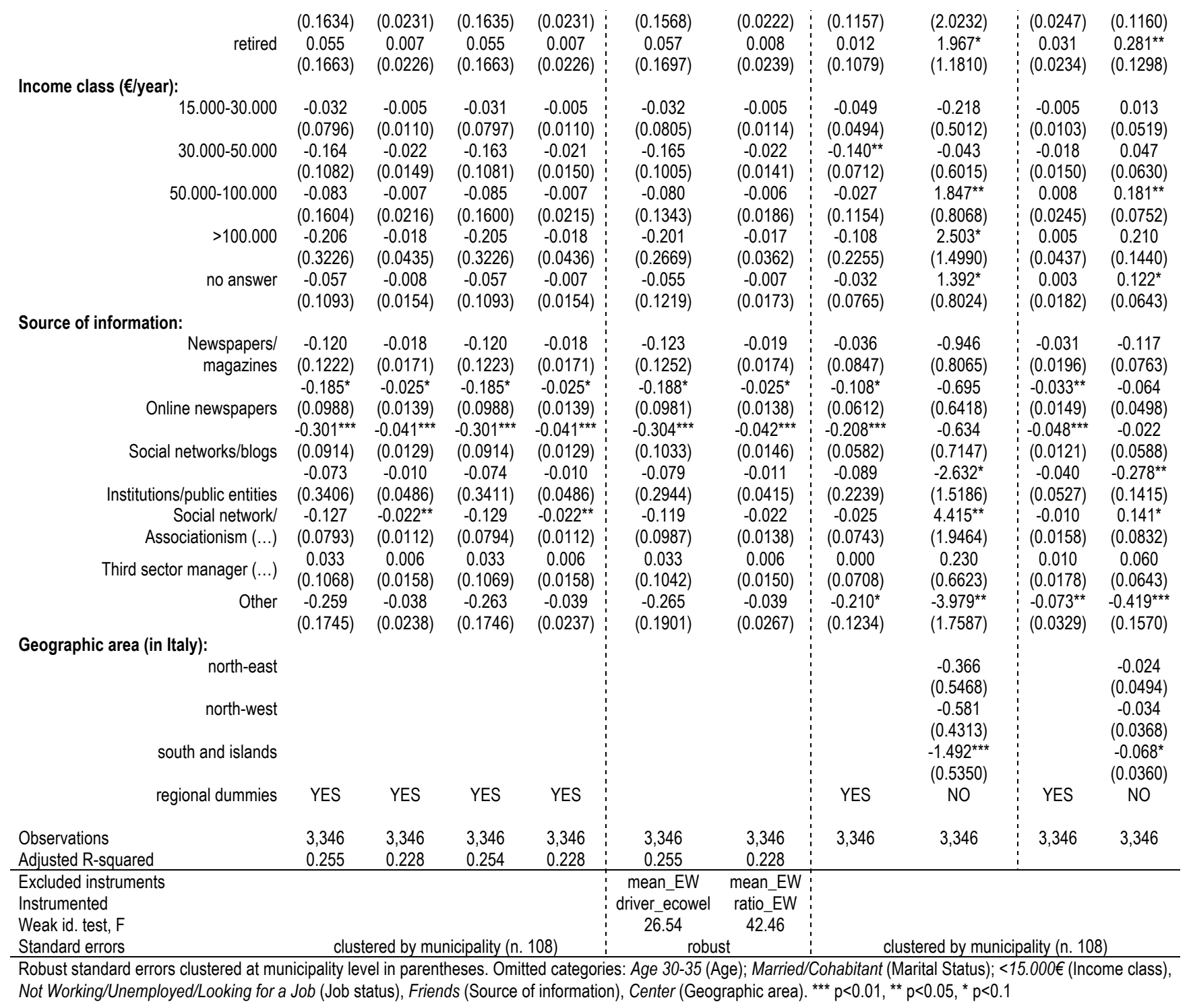




\section{APPENDIX B - Not for publication}

\section{The complete set of Indicators for each dimension of the BES composition}

\section{Environment}

1 Drinkable water: Volume of drinkable 1 water supplied every day per capita

2 Quality of marine coastal waters: Percentage of bathing marine coastal waters on total coasts

3 Quality of urban air: Number of exceeding the daily limit of PM10

4 Urban parks and gardens: Square meters of urban parks and gardens per inhabitants

5 Areas with hydrogeological risks: Percentage of areas subject to landslide on total surface

6 Contaminated sites: Number and size of contaminated sites

7 Terrestrial parks: Share of the size of terrestrial parks on total surface

8 Marine protected areas: Share of the size of marine protected areas on total coastal area

9 Areas of special naturalistic interest: Share of areas of special naturalistic interest of total surface

10 Concern for biodiversity loss: Percentage of people aged 14 and over who believe that biodiversity loss is among the five most important environmental problems

11 Material flows: Quantity of materials, transformed in emissions, waste or new stocks, limited to internal material consumption

12 Energy from renewable sources: Share of energy consumptions provided by renewable sources on total internal consumptions

13 Emissions of $\mathrm{CO} 2$ and other greenhouse gasses: Tons of $\mathrm{CO} 2$ equivalent per capita

\section{Health}

1 Life expectancy at birth: Life expectancy expresses the average number of years that a child born in a given calendar year can expect to live if exposed during his whole life to the risks of death observed in the same year at different ages. 2 Healthy life expectancy at birth: It expresses the average number of years that a child born in a given calendar year can expect to live in good health on the assumption that the risks of death and perceived health conditions remain constant. It is built using the prevalence of individuals who respond positively ("well" or "very well") to the question on perceived health.

3 Physical Component Summary (PCS): Summary of the scores of each individual answering the 12 questions on the questionnaire SF12 on physical state (Physical Component Summary).

4 Mental Component Summary (MCS): Summary of the scores of each individual answering the 12 questions on the questionnaire SF12 on psychological state (Mental Component Summary).

5 Infant mortality rate: Deaths during the first year of life per 10.000 born alive.

6 Traffic accidents (15-34 years old): Mortality rate for traffic accidents (initial cause) by five year age groups for people aged 15-34 years, standardized by the Italian 2001 Census population of the same age groups.

7 Age-standardised cancer mortality rate (19-64 years old): Mortality rate for cancer (initial cause) by five year age groups for people aged 19-64 years, standardized by the Italian 2001 Census population of the same age groups.

8 Age-standardised mortality rate for dementia and related illnesses (people aged 65 and over): Mortality rate for nervous system diseases and psychical and behavioral disorders (initial cause) by five year age groups for people aged 65 years and over, standardized by the Italian 2001 Census population of the same age groups.

9 Life expectancy without activity limitations at 65 years of age: It expresses the average number of years that a person aged 65 can expect to live without suffering limitations in daily activities due to health problems, assuming that the risks of death and disability remain constant over time and equal to those observed in a specific calendar year. It is based on the prevalence of individuals who answer to be limited, for at least the past 6 months, because of a health problem in activities people usually do.

10 Overweight or obesity - Standardized percentage of people aged 18 years and over who are overweight or obese: The indicator refers to the Body Mass Index (BMI), which classifies people as overweight $(25<=\mathrm{BMI}<30)$ or obese $(\mathrm{BMI}>$ 30 ) as classified by the World Health Organization (WHO). The indicator is standardized using the Italian 2001 Census population as standard population.

11 Smoking - Standardized percentage of people aged 14 years and over declaring to smoke: Proportion of people aged 14 and over who report current smoking. The indicator is standardized using the Italian 2001 Census population as standard population.

12 Alcohol consumption - Standardized percentage of people aged 14 years and over with at least one risk behaviour in alcohol consumption: Taking into account the definitions adopted by the WHO and the recommendations from INRAN, in agreement with the National Institute of Health, are identified as "at-risk consumers" all those individuals who have at least one risk behavior, exceeding the daily consumption of alcohol (according to specific thresholds for sex and age) 
or concentrating on a single occasion of consumption the intake of 6 or more units of any alcoholic drink (bing drinking).

13 Sedentariness - Standardized percentage of people aged 14 years and over who do not practice any physical activity: Proportion of people aged 14 and over referring not to play sports neither continuously nor intermittently during their spare time, and people aged 14 and over referring not to perform any physical activity, such as walking at least $2 \mathrm{~km}$, cycling, swimming, etc.

14 Nutrition - Standardized percentage of people aged 3 years and over who consume at least 4 portions of fruit and vegetables a day: Percentage of people aged 3 years and over who say they take every day at least 4 portions of fruit and vegetables. According to the guidelines for a healthy diet published by INRAN the recommended daily servings would be at least 5 , but since the definition of portion remains a difficult concept to be standardized for the Italian eating habits, although there are objective criteria of measurement, such as the weight of the food considered, it was considered appropriate to refer to the declared consumption of at least 4 portions. Very often, for example, a portion of vegetables taken as side dish is greater in quantity compared to the amount in grams recommended. The indicator is standardized using the Italian 2001 Census population as standard population.

\section{Economic wellbeing}

1 Per capita adjusted disposable income: Ratio of adjusted household disposable income (inclusive of the value of inkind services provided by public and non-profit institutions) to the total number of residents.

2 Disposable income inequality: Ratio of total equivalised income received by the $20 \%$ of the population with the highest income to that received by the $20 \%$ of the population with the lowest income.

3 People at risk of relative poverty: Percentage of persons at risk of poverty, with an equivalised income less than or equal to $60 \%$ of the median equivalised income.

4 Per capita net wealth: Ratio of total net wealth of households to the 4 total number of residents.

People living in financially vulnerable households: Percentage of people in households with debt service greater than $30 \%$ of disposable income.

5 People living in absolute poverty: Proportion of individuals belonging to households with an overall consumption expenditure below the threshold of absolute poverty.

6 Severely materially deprived people: Proportion of people living in households with at least 4 over 9 of the problems considered

7 People suffering poor housing conditions: Proportion of people experiencing overcrowding in houses without some services and with structural problems.

8 Index of subjective evaluation of economic distress: It is a combination of three indicators: (a) share of individuals in households choosing the first answer category to the question "Considering all the available income, how does your household manage to get to the end of the month?" (With great difficulty, with difficulty, with some difficulty, with some ease, with ease, very easily); (b) proportion of individuals living in households which are unable to cope with its own resources with unexpected expenses of approximately XXX euros (the value is calculated according to the median of the distribution of the equivalised income of the previous year); ( c) share of individuals who do not consider it possible to be able to make savings in the next 12 months.

9 People living in jobless households: Proportion of individuals living in households with at least one component aged 18-59 years (with the exception of households where all members are full time students under 25 years) where nobody works or receives an occupational pension.

\section{Education and training}

1 Participation in early childhood education: Children aged 4-5 years participating in pre-primary education / children aged 4-5 years

2 Percentage of people aged 25-64 having completed at least upper secondary education: Persons aged 25-64 years having completed at least upper secondary education (ISCED level not below 3a, 3b or 3c) / persons aged 25-64 years *100

3 Percentage of people aged 30-34 having completed tertiary education (ISCED 5 o 6): Persons aged 30-34 years having completed tertiary education (ISCED 5 o 6) / Persons aged 30-34 years * 100

4 Percentage of early leavers (aged 18-24) from education and training: Persons aged 18-24 years who have achieved only lower secondary (ISCED 2) and are not included in a training program / Persons aged 18-24 years * 100

5 Percentage of people aged 15-29 not in education, employment, or training (NEET): Persons aged 15-29 years that are not in education, employment, or training / Persons aged 15-29 years * 100

6 Percentage of people aged 25-64 participating in formal or non-formal education: Persons aged 25-64 years participating in formal or non-formal education / Persons aged 25-64 years * 100

7 Level of literacy: Scores obtained in the tests of functional literacy skills of students in the II classes of upper secondary education

8 Level of numeracy: Scores obtained in the tests of numeracy skills of students in the II classes of upper secondary education

9 Percentage of people aged 16 and over with high level of ICT competencies: Persons aged 16 years and over who can perform at least 5 over the 6 listed operations on the computer / persons aged 16 years and over * 100 
10 Synthetic indicator of the level of cultural participation: Based on the aggregation of the following indicators: percentage of people aged 6 and over that, in the 12 months preceding the interview, have gone at least once to: cinema, theatre, exhibitions and museums, archaeological sites, monuments, concerts of classical music, opera, concerts of other kind of music; percentage of people aged 6 and over who read the newspaper at least once a week, who read at least one book in the 12 months preceding the interview, who usually read some magazines (weekly or periodic), who watches DVDs at home.

\section{Work and life balance}

1 Employment rate of people 20-64 years old: Employed persons 1 aged 20-64 / persons aged 20-64*100 Nonparticipation rate: Unemployed persons aged 15-74 + part of the potential labour force aged 15-74 (persons who are inactive not having looked for a job in the past 4 weeks but willing to work) / Labour force aged 15-74 + part of the potential labour force aged 15-74 (persons who are inactive not having looked for a job in the past 4 weeks but willing to work)

2 Transition rate (12 months time-distance) from non-standard to standard employment: Persons employed in nonstandard jobs at the time $\mathrm{tl}$ (employees with temporary jobs + term-contract workers + project worker + occasional hired workers + single customer self-employed without employees) which have a standard job (permanent employees + self-employed with employees + no single customer self-employed without employees) a year later / Employed in nonstandard jobs at the time $\mathrm{t} 1 * 100$

3 Share of employed persons with temporary jobs for at least 5 years: Temporary employees and term-contract workers who began their current job at least 5 years prior to interview / Total Temporary employees and term-contract workers * 100

4 Share of employees with below 2/3 of median hourly earning: Employees with an hourly wage of less than 2/3 of the median / Total number of employees * 100

5 Share of over-qualified employed persons: Employees with a higher qualification than that mostly held to exercise a certain profession / Total employed population * 100

6 Incidence rate of fatal occupational injuries or injuries leading to permanent disability: Number of fatal occupational injuries or injuries leading to permanent disability/ Total employed population (excluding the armed forces) $* 1,000$

7 Share of employed persons not in regular occupation: Employees who do not comply with work, fiscal and pension laws / total employees

8 Ratio of employment rate for women 25-49 years with children under compulsory school age to the employment rate of women 25-49 years without children: Employment rate of women aged 25-49 with at least one children under compulsory school age / Employment rate of women aged 25-49 without children

9 Share of household work time carried out by women in a couple on the total of the household work time: Household work time carried out by women / household work time carried out by both partner * 100

10 Share of population aged 15-64 years that work over 60 hours per week (including paid work and household work): Population aged 15-64 years that work over 60 hours per week of paid work and household work / population aged 1564 years

11 Share of employees covered by collective bargaining at company or district level: Employees covered by collective bargaining at company or district level / total employees in companies with more than 10 employees

12 Share of employees that work in companies where there is trade union: Employees that work in companies where there is trade union / total employees * 100

13 Share of employed persons who feel their work unsecure: Employed persons who, in the following 6 months, consider it is likely they lose their job and it is not at all or a little likely that they find another similar job / Total employed persons * 100

14 Share of employed persons who feel satisfied with their work: The indicator is built as the average level of satisfaction (eg, using a scale from 0 to 10) in more than one dimension: the type of work, earnings, prospects of career, relations with others, working conditions and environment, reconciliation with lifetimes.

\section{Social relationships}

1 Synthetic indicator of social participation: Based on the aggregation of the following indicators: People aged 14 and over who during the past 12 months have participated in meetings of associations (cultural/recreational, ecological, civil rights, for peace); People aged 14 and over who in the past 12 months have participated in meetings of trade unions and of professional associations; People aged 14 and over who during the past 12 months have attended meetings of political parties and/or have worked free for a party; People aged 14 and over who pay monthly or periodical dues for a club/sports club; People aged 14 and over who during the past 12 months have participated in

meetings or activities (cultural, sporting, recreational, spiritual), organized or promoted from parishes, religious or spiritual organizations/groups.

2 Generalized trust: Share of population (aged 14 and over) who believes that most 2 of the people are trustworthy.

3 Non-profit organizations per 10,000 inhabitants: Number of non-profit organizations per 10,000 inhabitants

4 Social co-operatives per 10,000 inhabitants: Number of social co-operatives per 10,000 inhabitants

5 Volunteer work: Percentage of population aged 14 and over who in the past 12 months performed non-paid volunteer work for associations or volunteer groups. 
6 Provided aids: Share of population aged 14 and over who in past 12 months have given unpaid aid to non-cohabiting relatives and non-relatives.

7 Association funding: Share of population aged 14 and over who in the past 12 months have funded associations.

8 Satisfaction with family relationship: Share of population aged 14 and over who have declared to be very satisfied with his/her family relationships.

9 Satisfaction with friendship relationship: Share of population aged 14 and over who have declared to be very satisfied with the relationship with his/her friends.

10 Percentage of people of 14 years and over which have relatives, friends or neighbours on which they can count: Based on the aggregation of the following indicators: Share of people aged 14 and over who have relatives they can count on; Share of people aged 14 and over who have friends or neighbours they can count on.

11 Percentage of children aged 3 to 10 years who play with their parents: Based on the aggregation of the following indicators: Children aged 3-10 years who every day spend some time playing with his/her father; Children aged 3-10 years who every day spend some time playing with his/her mother.

\section{Security}

1 Homicide rate: Number of homicide / population * 100.000

2 Burglary rate: Number of burglaries / households * 100

3 Pick-pocketing rate: Number of pick-pocketing / population * 100

4 Robbery rate: Number of robberies / population * 100

Physical violence rate: Percentage of people aged 16 and over who were victim of physical violence / people aged 16 and over

5 Sexual violence rate: Percentage of people aged 16 and over who were victim of sexual violence / people aged 16 and over

6 Fear of crime rate: Percentage of people aged 14 years and over feeling unsafe when walking alone in the dark in the area where they live

7 Worries of sexual crime rate: Percentage of people aged 14 years and over who are very or quite worried of suffering a sexual violence

8 Concrete fear rate: Percentage of people aged 14 years and over who are afraid of becoming concretely a victim of crime

9 Social decay (or incivilities) rate: Percentage of people aged 14 years and over who often see elements of social and environmental decay (vandalism acts, people selling drugs, drugs users, prostitute looking for clients) in the area where they live

10 Intimate partnership violence rate: Number of women who were victim of physical or sexual violence by the partner /women who have or had a partner * 100

\section{Subjective wellbeing}

1 Percentage of people aged 14 and over with a level of life satisfaction from 8 to 10: Persons aged 14 and over with a level of life satisfaction from 8 to 10 / Persons aged 14 and over * 100

2 Percentage of people aged 14 and over very satisfied of their leisure time: Persons aged 14 and over who are very satisfied with their leisure time / Persons aged 14 and over * 100

3 Percentage of people aged 14 and over which believe their personal situation will improve in the next 5 years: Persons aged 14 and over which believe their personal situation will improve in the next 5 years / Persons aged 14 and over* 100

\section{Landscape and cultural heritage}

1 Endowment of cultural heritage items: The number of archaeological sites, monuments and museums surveyed by the

"Risk Map of Cultural Heritage" (an information system held by the Italian Ministry of Culture), per sq.km

2 Current expenditure of Municipalities for the management of cultural heritage (museums, libraries and art galleries), per capita

3 Illegal building rate: Ratio of the number of unauthorised buildings to the number of building permits issued by the Municipalities

4 Urbanisation rate of areas subject to building restrictions by virtue of the Italian laws on landscape protection: Number of buildings realised after 1981 in areas subject to building restrictions by the "Galasso Law" (no. 431/1985, as integrated by the Cultural Heritage and Landscape Code - Legislative Decrees no. 42/2004, no. 157/2006 and no. $63 / 2008)$, per sq.km

4 Erosion of farmland from urban sprawl: Percentage ratio of rural areas affected by urban sprawl to the total of rural areas ("rural areas affected by urban sprawl": rural areas with increasing population and decreasing agricultural land)

5 Erosion of farmland from abandonment: Percentage ratio of abandoned rural areas to the total of rural areas ("abandoned rural areas": rural areas with decreasing population and decreasing agricultural land)

6 Presence of historic rural landscapes: Percentage ratio of areas classified as such by the National Inventory of Historic Rural Landscapes to the total area of the Region 
7 Quality assessment of Regional programmes for rural development (PSRs), with regard to the landscape protection: Score assigned to the PSRs based on the adoption of measures of a potentially positive impact on the rural landscape, among those envisaged by the National Strategic Plan for Rural Development 2007-2013.

8 Presence of Historic Parks/Gardens and other Urban Parks recognised of significant public interest: Percentage ratio of the area of parks and gardens classified as "historic" and/or "of a significant public interest" by the Legislative Decree no. 42/2004 to the total area of the provincial capital Municipalities

9 Conservation of historic urban fabric: Share of inhabited buildings realised before 1919 and in excellent or good state on the total number of building realised before 1919

10 People that are not satisfied with the quality of landscape of the place where they live: Proportion of regional population reporting that the landscape of the place where they live is affected by evident deterioration

11 Concern about landscape deterioration: Proportion of population reporting, among the environmental problems for which they express more concern, the decay of landscape due to overbuilding

\section{Research and innovation}

1 Research intensity: Percentage of R\&D expenditure on GDP

2 Patent propensity: Patent applications to the EPO per million of inhabitants (complementary, per million of euros of GDP).

3 Percentage of knowledge workers on total employment: Percentage of employees with tertiary education (ISCED 5-6) in S\&T occupations (ISCO 2-3) on total employees.

4 Innovation rate of the national productive system: Percentage of enterprises with (process, product, organizational or marketing) innovation on total enterprises with 10 or more employees.

5 Percentage of product innovators: Percentage of enterprises with product innovation on total enterprises with 10 or more employees.

6 Productive specialization in high-tech and knowledge intensive sectors: Percentage of employees in high-tech and knowledge intensive services on total employees.

7 Internet use: Percentage of individuals aged 16-74 who used Internet at least once a week in the last 12 months.

\section{Quality of services}

1 Index of accessibility to hospitals with emergency room: Percentage of population living more than $\mathrm{X}$ minutes from an hospital with emergency room (threshold to be defined).

2 Beds in residential health care facilities: Beds in residential health care facilities per 1,000 inhabitants

3 Waiting lists: Individuals who renounced to see a specialist or to undertake a therapeutic treatment (non dental) because of the length of the waiting list.

4 Percentage of population served by natural gas: Percentage of individuals living in municipalities supplied with methane gas.

5 Separate collection of municipal waste: Percentage of municipal waste object of separate collection on total municipal waste.

6 Composite index of service accessibility: Percentage of individuals who find very difficult to reach some basic services (pharmacies, emergency, post office, police, carabinieri, municipal offices, crèches, nursery, primary and secondary school, markets and supermarkets).

7 Density of urban public transport networks: Km of urban public transport networks in provincial capitals per 100 $\mathrm{Km} 2$ of municipal surface.

8 Index of accessibility to transport networks: Percentage of population living more than X minutes away from a major train station (threshold to be defined).

9 Citizens who benefit from infancy services: Percentage of children aged 0-2 who benefited from infancy services (crèches, micro-crèches or supplementary and innovative services).

10 Elders who benefit from home assistance: Percentage of elders aged 65 and over who benefited from integrated home assistance services (ADI).

11 Prison density per 100 places: Percentage of prisoners in penal institutions on the 11 total capacity of penal institutions.

12 Irregularity in water supply: Percentage of families reporting irregularities in water supply.

13 Landfill of waste: Percentage of municipal waste going to landfill on total municipal waste collected.

14 Irregularity in electric power distribution: Frequency of accidental long lasting electric power cuts (cuts without notice longer than 3 minutes) (average number per consumer).

15 Time devoted to mobility: Minutes devoted to mobility on an average weekday.

\section{Policy and institutions}

1 Voter turnout: Percentage of eligible voter who cast a ballot in the last election for the European Parliament.

2 Civic and political participation: Based on the aggregation of the following indicators: Share of people aged 14 and over who talks about politics at least once a week; Share of people aged 14 and over who seek information about Italian politics at least once a week; Share of people aged 14 and over who in the past three months have taken part to online 
consultations or polls on civic/political issues (e.g. urban planning, signing a petition); Share of people aged 14 and over who in the past three months have read and posted on the web opinions on social/political issues.

3 Trust in the parliament: Percentage of people aged 14 and over who declared to trust the Italian Parliament.

4 Trust in judicial system: Percentage of people aged 14 and over who declared to trust the judicial system.

5 Trust in political parties: Percentage of people aged 14 and over who declared to trust political parties.

Trust in local institutions: Composite indicator based on the aggregation of the percentage of people aged 14 and over who declared to trust regional government, provincial government and municipal government.

6 Trust in other institutions: Composite indicator based on the aggregation of the percentage of people aged 14 and over who declared to trust the police and the fire brigade.

7 Women and political representation in Parliament: Share of women elected in Parliament.

8 Women and political representation at regional level: Share of women elected in regional councils.

9 Women in decision-making bodies: Share of women in position of high responsibility within the following bodies: Constitutional court, Magistrates' Governing Council, Regulatory authorities (competition, communication, privacy, securities market), Embassies.

10 Women in the boards of companies listed in stock exchange: Share of women in the boards of companies listed in stock exchange.

11 Median age of members of Parliament: Median age of members of Parliament

12 Length of civil proceedings of ordinary cognizance of first and second degree: Average time elapsed between entry and closing of proceedings. 


\section{APPENDIX C - Not for publication}

\section{What our well-being depends on?}

We aim to contribute with this questionnaire to the definition of what really matters in our life to improve our wellbeing. We, then, kindly ask you to answer to a few easy questions about the research issue stated before.

The collected data will be managed in compliance with the laws ruling the personal data protection (d. lgs. 196/2003 Code of ethics and conduct for the processing of personal data) and they will be used only for statistical and research purposes.

The questionnaire is divided into two sections: section 1 is about personal data while section 2 is about well-being.

Let's start asking you some pieces of information about you.

\section{Section 1: personal data}

1. Gender

M F

\section{Age}

Year of birth:

\section{Citizenship}

Italian

1

Not Italian

2 Country

(if 2 in the previous question)

How many years have you spent in Italy up to now?

Less than 1 1

From 1 to 3 years

2

From 3 to 5 years $\square$ 3

More than 5 years 4

\section{Residence}

City of residence ZIP code |_II_I__I_ I__ Province | L $|\ldots|$ 


\section{Education}

No titles

Primary school

Middle school

Technical vocational high schools (3 years) $\square \quad 4$

Upper secondary high school $\square \quad 5$

Bachelor degree $\square \quad \square$

Master of arts $\quad \square \quad 7$

Master $\quad \square \quad 8$

$\begin{array}{ll}\mathrm{PhD} & \square \quad 9\end{array}$

6. Civil status

Married/cohabitant

Single

Separate

Divorced

Widowed

7. Job status

Open-ended contract $\quad \square \quad 1$

Fixed term contract $\quad \square \quad 2$

Seasonal contract $\quad \square \quad 3$

Independent contractor/freelancer $\quad \square \quad 4$

Not working/unemployed/looking for a job $\quad \square \quad 5$

Redundancy fund benefits $\quad \square \quad 6$

$\begin{array}{ll}\text { Redundancy worker } & \square \quad 7\end{array}$

Housewife $\square \quad \square$

Student $\quad \square \quad 9$

Retired $\square \quad 10$

\section{Working sector}

Manufacturing $\square \quad 1$

Agriculture $\quad \square \quad 2$

Tertiary $\square \quad \square$

Personal services $\quad \square \quad 4$ 


\section{Family status}

Living alone

Living with my original family

Living with my partner without children

3

Living with my partner with children $\quad \square \quad 4$

I am the only parent of child/children $\quad \square \quad 5$

\section{Income class}

Less than $€ 15.000$ per year
Between $€ 15.000$ and $€ 30.000$ per year
Between $€ 30.000$ and $€ 50.000$ per year
Between $€ 50.000$ and $€ 100.000$ per year
More than $€ 100.000$ per year

\section{Political positioning}

How would you locate yourself in terms of political position between left and right wing on the following scale?

left wing

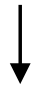

10

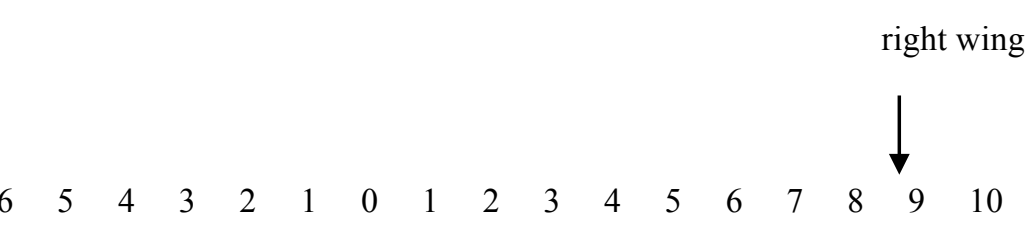

\section{How did you hear about this research?}

Newspapers/magazines

Online newspapers

Social networks/blogs

Institutions/public entities

Acquaintances/friends

Social network/third sector/Associationism and cooperation

Third sector manager training program

Other (please specify)
1

2

3

4

5

6 


\section{Sezione 2: Well-being}

13. Thinking about your overall current conditions how much do you feel happy?

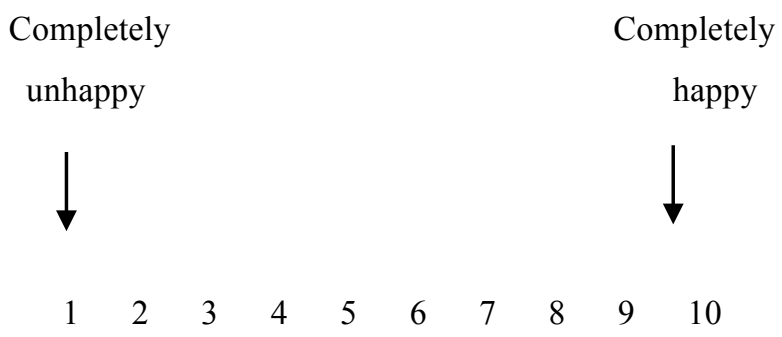

14. In particular, all in all, how much do you feel satisfied with regard to your:

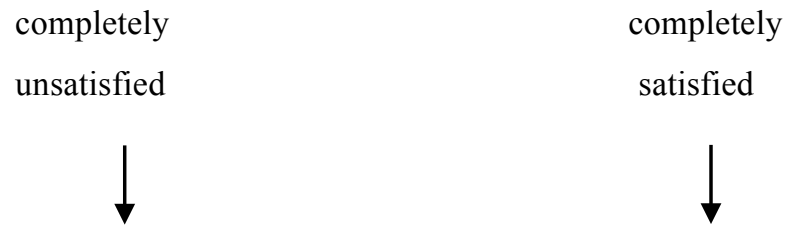

Economic condition

Health

Family members relationship

Friends relationships

Spare time

Overall life

$\begin{array}{llllllllll}1 & 2 & 3 & 4 & 5 & 6 & 7 & 8 & 9 & 10 \\ 1 & 2 & 3 & 4 & 5 & 6 & 7 & 8 & 9 & 10 \\ 1 & 2 & 3 & 4 & 5 & 6 & 7 & 8 & 9 & 10 \\ 1 & 2 & 3 & 4 & 5 & 6 & 7 & 8 & 9 & 10 \\ 1 & 2 & 3 & 4 & 5 & 6 & 7 & 8 & 9 & 10 \\ 1 & 2 & 3 & 4 & 5 & 6 & 7 & 8 & 9 & 10\end{array}$




\section{Wellbeing dimensions}

Below we offer 11 "dimensions of well-being," i. e. aspects of our everyday lives that have a positive or negative impact on the quality of life.

Imagine you have the responsibility of government and you have an amount equal to 100 units (eg 100 million euro) to spend and you can decide how to distribute these resources among the various items making sure, however, the total sum destined is equal to one hundred.

We realize that the "dimensions" of well-being reported are all very important, but we ask you to think carefully, to put the dimensions in relation to each other and to think about the relative importance of each of them from your point of view in order to use these resources in best way according to your point of view.
1) Health
2) Education and training
3) Work and life balance
4) Economic well-being
5) Social relations
6) Politics and institutions
7) Safety
8) Landscape and cultural heritage
9) Environment
10) Research and innovation
11) Quality of service 


\section{The aspects of well-being}

Below we offer a range of indicators affecting the well-being of each dimension given above. On which one among these aspects within each of the 11 categories you believe that the government has to spend more energy and resources in order to determine their improvement?

Choose the five most important items in order of priority

\section{A. Health}

On which of these aspects within the category HEALTH do you believe that the government has to spend more energy and resources in order to determine an improvement of well-being? ${ }^{1}$

1. Increasing life expectancy at birth.

2. Increasing healthy life expectancy at birth.

3. Improving individual physical state.

4. Improving individual psychological state.

5. Reducing infant mortality rate.

6. Reducing mortality rate for traffic accidents (initial cause).

7. Reducing cancer mortality rate (19-64 years old).

8. Reducing mortality rate for dementia and related illnesses (people aged 65 and over).

9. Increasing life expectancy without activity limitations at 65 years of age.

10. Reducing overweight or percentage of people aged 18 years and over who are overweight or obese.

11. Reducing the percentage of people aged 14 years and over declaring to smoke.

12. Reducing the percentage of people aged 14 years and over with at least one risk behavior in alcohol consumption.

13. Reducing the percentage of people aged 14 years and over who do not practice any physical activity.

14. Increasing the percentage of people aged 3 years and over who consume at least 4 portions of fruit and vegetables a day.

\footnotetext{
${ }^{1}$ For further details on each indicator see Appendix B.
} 


\section{B. Education and training}

On which of these aspects within the category EDUCATION AND TRAINING do you believe that the government has to spend more energy and resources in order to determine an improvement of well-being? ${ }^{2}$

1. Increasing participation in early childhood education

2. Increasing the number of people with at least upper secondary education

3. Increasing the number of people with tertiary education

4. Reducing the number of early leavers from education and training

5. Reducing the number of young not in education, employment, or training (NEET)

6. Increasing participation in long-life learning

7. Increasing the level of literacy

8. Increasing the level of numeracy

9. Increasing the number of people with high level of ICT competencies

C. Work and life balance

On which of these aspects within the category WORK AND LIFE BALANCE do you believe that the government has to spend more energy and resources in order to determine an improvement of well-being? ${ }^{3}$

1) Increasing employment rate

2) Decreasing the Non-participation rate

3) Increasing the transition rate

4) Decreasing the share of employed persons with temporary jobs for at least 5 years

5) Decreasing share of employees with below $2 / 3$ of median hourly earnings

6) Decreasing the share of over-qualified employed persons

7) Reducing the incidence rate of fatal occupational injuries or injuries leading to permanent disability

8) Decreasing the share of employed persons not in regular occupation

\footnotetext{
${ }^{2}$ For further details on each indicator see Appendix B.

${ }^{3}$ For further details on each indicator see Appendix B.
} 
9) Increasing the ratio of employment rate for women 25-49 years with children under compulsory school age to the employment rate of women 25-49 years without children Easing work-life balance for women with young children

10) Decreasing the share of population aged 15-64 years that work over 60 hours per week

11) Decrease the share of household work time carried out by women in a couple on the total of the household work time.

D. Economic well-being

On which of these aspects within the category ECONOMIC WELL-BEING do you believe that the government has to spend more energy and resources in order to determine an improvement of well-being? ${ }^{4}$

1. Increasing per capita adjusted disposable income

2. Increasing disposable income inequality

3. Reducing the number of people at risk of relative poverty

4. Increasing per capita net wealth

5. Reducing the number of people living in financially vulnerable households

6. Reducing the number of people living in absolute poverty

7. Reducing the number of severely materially deprived people

8. Reducing the number of people suffering poor housing conditions

9. Reducing subjective evaluation of economic distress

10. Reducing the number of people living in jobless households

\footnotetext{
${ }^{4}$ For further details on each indicator see Appendix B.
} 


\section{E. Social Relations}

On which of these aspects within the category SOCIAL RELATIONS do you believe that the government has to spend more energy and resources in order to determine an improvement of well-being? ${ }^{5}$

1. Increasing satisfaction with family relationship

2. Satisfaction with friendship relationship

3. Percentage of people of 14 years and over which have relatives, friends or neighbors on which they can count

4. Percentage of children aged 3 to 10 years who play with their parents

5. Provided aids: share of population aged 14 and over who in past 12 months have given unpaid aid to non-cohabiting relatives and non-relatives.

6. Synthetic indicator of social participation: Based on the aggregation of the following indicators: People aged 14 and over who during the past 12 months have participated in meetings of associations (cultural/recreational, ecological, civil rights, for peace); People aged 14 and over who in the past 12 months have participated in meetings of trade unions and of professional associations; People aged 14 and over who during the past 12 months have attended meetings of political parties and/or have worked free for a party; People aged 14 and over who pay monthly or periodical dues for a club/sports club; People aged 14 and over who during the past 12 months have participated in meetings or activities (cultural, sporting, recreational, spiritual), organized or promoted from parishes, religious or spiritual organizations/groups.

7. Volunteer work: Percentage of population aged 14 and over who in the past 12 months performed non- paid volunteer work for associations or volunteer groups.

8. Association funding: Share of population aged 14 and over who in the past 12 months have funded associations.

9. Non-profit organizations per 10,000 inhabitants

10. Social cooperatives per 10,000 inhabitants

11. Generalized trust: Share of population (aged 14 and over) who believes that most 2 of the people are trustworthy.

\footnotetext{
${ }^{5}$ For further details on each indicator see Appendix B.
} 


\section{F. Politics and Institutions}

On which of these aspects within the category POLITICS AND INSTITUTIONS do you believe that the government has to spend more energy and resources in order to determine an improvement of well-being? ${ }^{6}$

1. Increasing electoral participation

2. Increasing civic and political participation

3. Increasing confidence in the Italian Parliament

4. Increasing confidence in the judicial system

5. Increasing trust in political parties

6. Increasing trust in local institutions

7. Increasing trust in other types of institutions

8. Increasing the percentage of women and political representation in Parliament

9. Increasing the percentage of women and political representation at the local level

10. Increasing the percentage of women in decision-making bodies

11. Increasing the percentage of women on boards of directors of companies listed in the Italian stock exchange

12. Reducing the average age of the Italian Parliament

13. Reducing the length of civil proceedings.

\footnotetext{
${ }^{6}$ For further details on each indicator see Appendix B.
} 


\section{G. Safety}

On which of these aspects within the category SAFETY do you believe that the government has to spend more energy and resources in order to determine an improvement of well-being? ${ }^{7}$

1. Reducing homicide rate.

2. Reducing burglary rate.

3. Reducing pick-pocketing rate.

4. Reducing robbery rate

5. Reducing physical violence rate

6. Reducing sexual violence rate

7. Reducing intimate partnership violence rate.

8. Reducing worries of being victim of a sexual offence.

9. Reducing Fear of crime rate.

10. Reducing concrete fear rate.

11. Reducing social decay (or incivilities) rate.

\footnotetext{
${ }^{7}$ For further details on each indicator see Appendix B.
} 


\section{H. Landscape and cultural heritage}

On which of these aspects within the category LANDSCAPE AND CULTURAL HERITAGE do you believe that the government has to spend more energy and resources in order to determine an improvement of well-being? ${ }^{8}$

1. Increasing the endowment of cultural heritage items

2. Increasing current expenditure of Municipalities for the management of cultural heritage (museums, libraries and art galleries), per capita

3. Reducing Illegal building rate

4. Reducing urbanization rate of areas subject to building restrictions by virtue of the Italian laws on landscape protection

5. Reducing the erosion of farmland from urban sprawl

6. Reducing the erosion of farmland from abandonment

7. Increasing the presence of historic rural landscapes

8. Enhancing quality assessment of Regional programmers for rural development (PSRs), with regard to the landscape protection

9. Increasing the presence of Historic Parks/Gardens and other Urban Parks recognized of significant public interest

10. Promoting conservation of historic urban fabric

11. Reducing the number of people that are not satisfied with the quality of landscape of the place where they live

12. Reducing concern about landscape deterioration

\footnotetext{
${ }^{8}$ For further details on each indicator see Appendix B.
} 


\section{Environment}

On which of these aspects within the category ENVIRONMENT do you believe that the government has to spend more energy and resources in order to determine an improvement of well-being? ${ }^{9}$

1. Increasing access to drinkable water

2. Increasing quality of marine coastal waters

3. Increasing quality of urban air

4. Increasing urban green

5. Reducing areas with hydrogeological risks

6. Reducing contaminated sites

7. Increasing surfaces of terrestrial parks

8. Increasing surfaces of marine protected areas

9. Increasing surfaces of areas of special naturalistic interest

10. Reducing concern for biodiversity loss

11. Reducing material flows (Quantity of materials, transformed in emissions, waste or new stocks, limited to internal material consumption)

12. Increasing use of energy from renewable sources

13. Reducing emissions of $\mathrm{CO} 2$ and other greenhouse gasses

\footnotetext{
${ }^{9}$ For further details on each indicator see Appendix B.
} 


\section{J. $\quad$ Research and development}

On which of these aspects within the category RESEARCH AND DEVELOPMENT do you believe that the government has to spend more energy and resources in order to determine an improvement of well-being? ${ }^{10}$

1. Intensity of research

2. Propensity: to patent

3. Impact of knowledge workers on employment

4. Innovation rate of the productive system

5. Innovation rate of product/service of the national productive system

6. Productive specialization in knowledge-intensive sectors

7. Intensity of Internet use

\footnotetext{
${ }^{10}$ For further details on each indicator see Appendix B.
} 